Review Article

\title{
The Combination of Physical Exercise with Muscle-Directed Antioxidants to Counteract Sarcopenia: A Biomedical Rationale for Pleiotropic Treatment with Creatine and Coenzyme Q10
}

\author{
Michele Guescini, ${ }^{1}$ Luca Tiano, ${ }^{2}$ Maria Luisa Genova, ${ }^{3}$ Emanuela Polidori, ${ }^{1}$ Sonia Silvestri, ${ }^{2}$ \\ Patrik Orlando, ${ }^{2}$ Carmela Fimognari, ${ }^{4}$ Cinzia Calcabrini, ${ }^{1,4}$ Vilberto Stocchi, ${ }^{1}$ and \\ Piero Sestili ${ }^{1}$
}

${ }^{1}$ Department of Biomolecular Sciences, University of Urbino Carlo Bo, Urbino, Italy

${ }^{2}$ Department of Life and Environmental Sciences (DISVA), Marche Polytechnic University, Ancona, Italy

${ }^{3}$ Department of Biomedical and Neuromotor Sciences, Alma Mater Studiorum, University of Bologna, Bologna, Italy

${ }^{4}$ Department for Life Quality Studies, Alma Mater Studiorum, University of Bologna, Rimini, Italy

Correspondence should be addressed to Piero Sestili; piero.sestili@uniurb.it

Received 5 June 2017; Revised 13 August 2017; Accepted 23 August 2017; Published 20 September 2017

Academic Editor: Guilherme Bresciani

Copyright (C) 2017 Michele Guescini et al. This is an open access article distributed under the Creative Commons Attribution License, which permits unrestricted use, distribution, and reproduction in any medium, provided the original work is properly cited.

\begin{abstract}
Sarcopenia represents an increasing public health risk due to the rapid aging of the world's population. It is characterized by both low muscle mass and function and is associated with mobility disorders, increased risk of falls and fractures, loss of independence, disabilities, and increased risk of death. Despite the urgency of the problem, the development of treatments for sarcopenia has lagged. Increased reactive oxygen species (ROS) production and decreased antioxidant (AO) defences seem to be important factors contributing to muscle impairment. Studies have been conducted to verify whether physical exercise and/or AOs could prevent and/or delay sarcopenia through a normalization of the etiologically relevant ROS imbalance. Despite the strong rationale, the results obtained were contradictory, particularly with regard to the effects of the tested AOs. A possible explanation might be that not all the agents included in the general heading of "AOs" could fulfill the requisites to counteract the complex series of events causing/accelerating sarcopenia: the combination of the muscle-directed antioxidants creatine and coenzyme Q10 with physical exercise as a biomedical rationale for pleiotropic prevention and/or treatment of sarcopenia is discussed.
\end{abstract}

\section{Introduction}

Sarcopenia, that is, age-associated muscle weakness and reduced muscle mass, is characterized by a decrease in muscle fiber number and size, slower contraction speed, shift in fiber type composition, and changes in various metabolic parameters. These features link to muscular dysfunction [1], namely, the loss of strength and performance, with a risk of adverse outcomes such as falls and fractures, impaired ability to perform activities of daily living, and increased risk of death [2].
Sarcopenia is not a disease but a syndrome caused by multiple factors [3]: among these, oxidative stress and mitochondrial dysfunction have long been reported. Although the oxidative stress theory of aging is under continuous reappraisal [4] taking into account, for example, the hormetic nature of reactive oxygen species (ROS) along with the merging of different theories in a new one, there is accumulating evidence that the biological process of aging is characterized by oxidative stress and mitochondrial dysfunction [5], which in turn result in a significant decline of aerobic capacity in the senescent muscle [6]. 
Although the reasons for the increased ROS production in aged subjects are still not entirely clear, the analysis of the literature shows that age-related defects in the mitochondrial respiratory chain (MRC) are considered a crucial factor [7]. In particular, the production of superoxide by complex I (NADH-ubiquinone oxidoreductase) is strongly dependent on the plasticity of the supramolecular organization of the MRC [8], which may modulate the conformational state of this multisubunit enzyme complex, the stability of its ROSgenerating domain, and the consequent leak of electrons [9], despite the absence of manifested genetic defects. Furthermore, the arrangement of active sites within the supercomplex architecture may help to limit ROS production by complex III (ubiquinol-cytochrome c oxidoreductase) [10]. In our hypothesis, the dissociation of respiratory supercomplexes may therefore link to age-associated oxidative stress and energy failure in a vicious circle also including membrane lipid peroxidation and mtDNA damage as possible concurring factors [11].

Such a situation may lead to a profound imbalance of ROS physiological signalling [12], which plays a pivotal and positive role in muscle homeostasis and function, particularly in the adaptive response to physical exercise [13]. In fact, a relatively mild action of ROS produced during exercise leads to ergogenic and adaptive stimuli. Otherwise, if the cell is overwhelmed by the action of ROS, then subcellular damage, signalling dysregulation, and aging will take place.

The dual nature of ROS (i.e., as a general feature of detrimental damage to cellular structures in aging and as secondary messengers) is also highlighted by recent results [14] illustrating that increasing ROS production specifically from over-reduced coenzyme Q (CoQ) pool and through respiratory complex I reverse electron transport generates a ROS signal necessary for cell homeostasis, which extends Drosophila lifespan despite reducing mitochondrial respiration. Scialo et al. [14] conclude that, if such mechanism is conserved in mammals, manipulation of the redox state of CoQ may be a strategy for the extension of both mean and maximum lifespan and the road to new therapeutic interventions for aging and age-related diseases.

The age-related imbalance between ROS and antioxidant (AO) defences is also reputed as a primary cause of detrimental chronic inflammatory reactions in human skeletal muscle $[15,16]$. Another emerging line of reasoning considers the contribution of epigenetic pathways both at nuclear and at mitochondrial levels. The epigenetic mechanisms involved in the aging process include alterations of the DNA methylation status, modifications of the histone tails (mainly acetylation and methylation), and changes in the expression of noncoding RNAs [17]. These modifications are strictly dependent on the cellular energy status and can be influenced by nutritional habits and cellular stress conditions, including excessive mitochondrial ROS levels [18].

There is currently no optimal treatment for sarcopenia. Potential intervention strategies for relieving the symptoms of the syndrome include physical activity, hormone administration, caloric restriction, and nutritional interventions including intake of supplementary AOs [19].
As to physical activity, it is increasingly considered as a promising strategy to limit age-related sarcopenia due to the potent associated adaptive response [20]. In fact, exercise interventions improve the quality of life in older adults and, in particular, resistance exercise effectively modulates muscle mass and function $[21,22]$. From a molecular point of view, for example, exercise training has been shown to ameliorate systemic AO capacity [23] and to delay the age-related decrease of DNA repair capacity [24] and of mitochondrial biogenesis [25].

At the same time, since increased muscle contraction in elderly people may lead to unmatched ROS production, it has been suggested to adopt supplementation regimens with dietary AOs. However, this assumption is controversial due to the lack of strong evidence indicating adverse and/or positive effects of combining exercise training with dietary supplementation with generic AOs [26].

Considering this last notion, that is, the hormetic nature of ROS and the complexity of the diverging responses they elicit, the combination of exercise training with rationally selected, muscle-directed AOs, namely, creatine $(\mathrm{Cr})$ and coenzyme Q10 (CoQ10), is discussed in this review.

\section{The Multifactorial Link between Sarcopenia and Oxidative Stress}

Sarcopenia has been defined as the presence of both low muscle mass and low muscle function that occurs with advancing age [1]. Age-associated muscle weakness and reduced muscle mass are characterized by a decrease in muscle fiber number and size, slower contraction speed, shift in fiber type composition, and changes in various metabolic parameters. These alterations are associated with an agerelated decline in several whole-body physiological variables, such as maximal oxygen uptake, endurance performance, insulin sensitivity, muscle power, and strength [27-29].

Here, we focus on the relationships between ageassociated oxidative imbalance/stress and sarcopenia. Since oxidative stress is not the only cause of muscle aging, for a more comprehensive review on the etiopathological factors and mechanisms involved in sarcopenia, see [30].

Sarcopenia is caused by both intrinsic and extrinsic factors [3]. Among these factors [30], oxidative stress and mitochondrial dysfunction are known to participate in the aging process of the skeletal muscle and other organs $[31,32]$. Muscle mitochondrial dysfunction may cause both loss of mitochondrial density and impairment of oxidative phosphorylation due to lower respiratory capacity resulting in reduced ATP production [6]: this evidence led to the proposal of the "mitochondrial theory of sarcopenia" [33].

The age-associated increase of ROS causes damage to macromolecules, in particular, to MRC components, which further increases the production of free-radicals resulting in the accumulation of mitochondrial damage and ineffective mitochondria quality control $[31,33]$.

Defective operation of the enzyme complexes of the MRC constitutes a key mechanism involved in the age-associated loss of bioenergetic reserve capacity and enhanced electron leakage from complexes I, II, and III. However, it is worth 
noting that the primary event responsible for aging may be the structural damage of both lipids and proteins, as induced by ROS directly and indirectly via the alteration of the signalling pathways modulating the mitochondrial activity [11]. Peroxidation of bioactive lipids and phospholipids of the inner mitochondrial membrane can perpetuate a vicious circle by hampering the supramolecular organization of the respiratory supercomplex $\mathrm{I}_{1} \mathrm{III}_{2}$ (SC) [34] thus favouring further generation of the superoxide anion radical by complex I, which eventually leads to catastrophic metabolic deficiency of mitochondria. One of the first signals in mitochondria is oxidized cardiolipin (CL) [35]. Bound CL molecules are seen in the crystal structures of the respiratory complexes and have been recently shown to stabilize, indeed, the respiratory supercomplexes. Selective peroxidation of CL, which in the animal variant carries polyunsaturated fatty acid chains, was demonstrated in response to mitochondrial oxidative stress in various experimental models, and among others, a consequence of CL peroxidation is the alteration of the supercomplex assembly with impaired MRC function; see [36] for review. Indeed, disaggregation of SC and the consequent loss of CoQ buried in its interface still allow electron transfer through a free CoQ pool in the membrane lipid bilayer, but in a less efficient way because the CoQ content in mitochondria is not saturating for maximal respiratory activity. In fact, Lenaz et al. [36] demonstrated that electron transfer between complex I and complex III (i.e., NADHcytochrome c oxidoreductase activity) in isolated bovine heart mitochondria can take place at a high rate as long as the SC organization is not destroyed by in vitro treatment with high-dose $\mathrm{n}$-dodecyl- $\beta$-D-maltoside. These data can be interpreted as maintenance of facilitated CoQ channeling within the respiratory SC as long as the SC itself is preserved, whereas NADH-cytochrome c oxidoreductase activity significantly decreases when electron transfer in the CoQ region occurs under conditions of less efficient collision-based pool behaviour (see also Section 6). As a consequence, the alteration of electron transfer may elicit strong enhancement of ROS generation. Several additional observations in cellular and animal models link together SC dissociation and enhanced ROS production [37-39].

Muscle cell aging is also characterized by a build-up of oxidatively modified proteins. The steady-state level of oxidized proteins depends on the balance between the rate of protein oxidative damage and the rates of protein degradation and repair. The proteasomal system is the major intracellular proteolytic pathway implicated in the degradation of oxidized proteins, and its function declines progressively with age. Therefore, the accumulation of oxidized proteins can be due to increased protein damage, decreased oxidized protein degradation and repair, or the combination of both mechanisms [40].

The complex scenario described so far also implies derangement in ROS-mediated cell signalling [41]. Redox signalling refers to a unique signal transduction pattern wherein some ROS serve as signalling molecules to modulate specific residues of the targets that cause changes in enzyme activity, transcription factor/cofactor association/dissociation, DNA binding, and gene expression $[42,43]$.
Alteration of the signalling network involving ROS has received increasing recognition over the past two decades [12]. Such alteration/dysregulation phenomena caused by excessive ROS also play an important role in sarcopenia. To this regard, however, it is important drawing some considerations. Firstly, ROS are not only detrimental: indeed, physiological ROS levels promote the activation of signalling cascades contributing to muscle homeostasis; secondly, the concept of "excessive" is not absolute, depending on the balance with cellular AO defences and cellular conditions [44]; and thirdly, even the lack of ROS may cause a detrimental cessation of signalling cascades important for muscle physiology [5, 44]. Given this premise, the most relevant redox-sensitive signalling pathways which may be imbalanced by excessive ROS are NF- $\kappa$ B [45], MAPKs [46] and PGC-1 $\alpha$ [47], and Akt/mTOR [48]. Indeed, all these paths are activated by exercise and one of the major mechanisms of their activation relies on the increase of $\mathrm{H}_{2} \mathrm{O}_{2}$ levels [5] within a physiologically compatible range.

For example, NF- $\kappa \mathrm{B}$ responsive elements are present in the promoter regions of genes encoding catalase, glutathione peroxidases, and $\mathrm{Mn}$ - and $\mathrm{Cu}-\mathrm{Zn}$-superoxide dismutase [49]. PGC- $1 \alpha$ is an inducible transcriptional coactivator participating in almost all aspects of mitochondrial functions ranging from energy fuel selection, muscle fiber differentiation and transformation, $\mathrm{AO}$ gene expression, and mitochondrial biogenesis to fusion and fission dynamics [50, 51]. PGC- $1 \alpha$ has been implicated as a major regulator of the mitochondrial biogenesis through the interaction with NRF-1 that stimulates the transcription of many mitochondrial genes as well as TFAM, a direct regulator of mitochondrial DNA replication and transcription [52]. PGC- $1 \alpha$ has a direct role in preserving muscle plasticity [47], and its age-related downregulation may play an important role in the decline of mitochondrial biogenesis and turnover contributing to the aetiology of sarcopenia $[53,54]$.

Mitochondrial function also depends on the coordination of nuclear and mitochondrial genomes, and therefore, the transcription and translation of both are coregulated. In fact, on one hand, the nucleus controls the mitochondrial function by promoting biogenesis and regulating mitochondrial activity to meet the cellular needs ("anterograde-regulation"); on the other, mitochondria can control the expression of nuclear genes modifying cellular function by reprogramming its metabolism ("retrograde response"). The study of mitonuclear communication has received great interest since it constitutes a robust network maintaining cellular homeostasis, regulating the adaptation to a variety of stressors, and promoting longevity [18].

With regard to mTOR signalling, its interplay with ROS is very complex, since ROS play both activating and inhibitory roles. Increasing evidence suggests that $\mathrm{mTORC} 1$ is a critical ROS mediator [55]. Recently, the effect of excessive ROS accumulation on the PI3K/AKT/mTOR signalling axis was evidenced by the near complete inhibition of mTORC1 activity as reflected by a decrease of the phosphorylated forms of proteins that are immediately downstream of the mTORC1 complex, namely, 4EBP1, p70S6K, and rpS6 [56, 57]. 
It is worth noting that the events described in this section are not limited to free radicals participating in signalling cascades themselves but may also be related to changes in the redox potential of different cellular compartments involved in redox-sensitive cascades according to their intrinsic susceptibility [58].

Oxidative stress does not only act as a direct effector of inflammation but also appears to be a primary causal factor in producing a chronic state of low-grade inflammation through activation of redox-sensitive transcription factor $\mathrm{NF}-\kappa \mathrm{B}$ [59]. Age-associated mitochondrial overproduction of ROS not only deregulates intracellular signalling but also affects intercellular communication. In particular, oxidative damage promotes senescence of cells, which in turn acquire a senescence-associated secretory phenotype characterized by the release of proinflammatory cytokines and several miRNAs [60] that alter the intercellular milieu and finally lead to inflammaging. Moreover, low-grade inflammation alters cellular protein metabolism to favour proteolysis over synthesis, thereby accelerating muscle atrophy [61] probably through the accumulation of $\mathrm{TNF} \alpha$ and proinflammatory cytokines that in turn leads to protein degradation via proteasome activation and reduced skeletal muscle protein synthesis.

Recent studies support the idea that aging impacts on muscle stem cell function in terms of their capacity to selfrenew, thus altering the composition of muscle niche. Moreover, a growing body of evidences points towards crosstalk between intrinsic (ROS, mitochondrial dysfunction, etc.) and extrinsic (circulatory factors and altered muscle niche) factors that on the whole contribute to poor efficiency of the muscle repair capacity at a geriatric age [3]. Muscle niche is regulated by growth and trophic factors, cytokines, and extracellular miRNAs carried by exosomes [62]. Extracellular miRNAs are modulated by exercise, immobilization, and muscular diseases. In addition, the expression of several miRNAs is also altered during aging [63].

Counteracting muscle mass loss during aging is a strong predictor for longevity in humans [64]. However, there is currently no optimal treatment for sarcopenia: potential intervention strategies include, among others, physical activity and nutritional supplementation (e.g., AOs) [19].

\section{The Hormetic Nature of Exercise Training in the Elderly}

Physical exercise has been shown to activate various redoxsensitive signalling pathways that control mitochondrial biogenesis, AO defence, inflammation, protein turnover, apoptosis, and autophagy $[5,65]$. Although these stimulatory effects of exercise decline with aging, they are not completely abolished. As a consequence, the stimulation of these residual capacities through exercise training represents an effective countermeasure against aging-associated transcriptional remodelling. In line with this evidence, it has been shown that the magnitude of increase in aerobic capacity following endurance training in older individuals is similar to that in younger subjects [66]. Thus, aged people can still benefit from regular physical activity in the appropriate forms and at proper intensity to preserve muscle function.
Indeed, there is a growing body of evidence showing that exercise interventions improve the quality of life in older adults [21] and particularly resistance exercise effectively modulates muscle mass and function in elderly people $[22,67]$.

Exercise training impacts muscle function through epigenetic mechanisms including histone deacetylation and loss of promoter methylation that modify exercise-responsive gene expression (i.e., PGC- $1 \alpha$, TFAM, and MEF2A), even after an acute bout of exercise, triggering structural and metabolic adaptations in skeletal muscle [68].

Physical exercise-mediated muscle health and longevity also involve sirtuin-1-regulated pathways promoting mitochondrial function and reduces the production of ROS through regulation of PGC- $1 \alpha$, the master controller of mitochondrial biogenesis [69], along with increased NRF-1 and TFAM levels. This results in increased mitochondrial oxidative capacity and ATP production, enhanced expression of tricarboxylic acid cycle and MRC enzymes, higher fatty acid oxidation, and mitochondrial morphological changes [47].

In particular, increased expression of PGC- $1 \alpha$ in muscle not only promotes mitochondrial biogenesis, enhances aerobic metabolism, and mimics the benefits of endurance training but also augments AO defences [53]. In addition, increased muscle PGC- $1 \alpha$ activity delays several age-related metabolic defects, such as chronic inflammation and reduction in insulin sensitivity, thus causing important consequences at systemic level. These effects of PGC- $1 \alpha$ activity in muscles presumably result from several PGC- $1 \alpha$ regulated processes, including resistance to oxidative stress [53], inhibition of atrophy [70], regulation of muscle metabolism, and release of myokines [71].

Moreover, using animal models, it has been demonstrated that endurance exercise rescues mitochondrial defects and premature aging of mice with defective proofreading exonuclease activity of mitochondrial DNA polymerase $\gamma$ [72]; exercise protects animals from neurodegeneration [73, 74] and can extend lifespan in rats [75], and it has been hypothesized that it could improve life expectancy in humans [76].

In older humans, beyond muscle mass, resistance training could modify the balance between oxidants/AOs by improving AO defences. According to this view, it has been reported that resistance training reduces the $8-\mathrm{OHdG} /$ creatinine ratio in urine, an effect that Parise et al. [77] hypothesized to depend on an upregulation of glutathione peroxidase activity [77]. However, recent literature suggests that improvements are closely related to the intensity of training protocols that must contain sufficient volume for each muscle group (3-5 sets, 10 repetitions) and intensities between 50 and $80 \%$ of 1 repetition maximum [41].

Increased muscle loading induces adaptive responses through a myriad of intracellular signalling events such as activation of the Akt/mTOR $[48,78,79]$ and myostatin pathways [80]. In addition to myostatin, contracting muscle produces other myokines including insulin-like growth factor-1 (IGF-1) [81]. Although muscle-derived IGF-1 is not detected in the circulation [82], it induces muscle hypertrophy in an autocrine/paracrine fashion following exercise [83]. 
Besides stimulating muscular anabolism, exercise inhibits protein degradation. Indeed, PI-3K/Akt inhibits the forkhead box transcription factor $\mathrm{O}$ (Fox-O), a potent inducer of the ubiquitin-proteasome system, and mTOR decreases caspases activity. Furthermore, physical inactivity stimulates Fox-O, which can also inhibit the mTOR pathway [84]. Furthermore, recent evidence shows that physical exercise, in the form of both endurance and resistance training, induces autophagy with metabolic beneficial effects $[85,86]$. Although the function of exercise-induced autophagy is still unclear, it is widely accepted that autophagy may be particularly important in a sarcopenic muscle by promoting the turnover of cellular components through the removal of damaged proteins and organelles.

Since satellite cells are critical players in skeletal muscle plasticity and repair, they have been suggested to be involved in the development of sarcopenia. Even if there is controversy as to whether satellite cells actually decrease in number with aging [87-89], their proliferative response and regenerative capacity are reduced in the aged muscle $[90,91]$. Evidence indicates that reduced regenerative function is more likely the result of a less optimal cellular environment than the cells being deficient due to age [3]. Exercise can enhance the activity of stem cells, including muscle satellite cells. Recent studies show that the increase in muscle mass and myonuclear content in response to exercise is accompanied by an increase in the number and activation status of satellite cells [92]. On the whole, it has been shown that regular exercise has a significant effect on the prevention of these ageassociated losses [93]. Chronic exercise could be considered as an effective measure against age-induced oxidative stress by improving pleiotropic responses able to scavenge ROS and repair damaged molecules/organelles [94].

Nevertheless, the available information shows that acute exercise increases ROS production and oxidative stress damage in older adults; this paradoxical effect is due to the ability of the exercise itself to increase the formation of ROS to a level that may induce significant yet tolerable damage, which can, in turn, promote beneficial adaptations [95].

In general, exercise at high intensity or for a long duration can enhance ROS and free radical production, induce damage in various tissues [96], and decrease circulating AOs (uric acid, SH-groups, alpha-tocopherol, beta-carotene, and retinol) [97]. However, exercise at moderate intensity and duration can generally be regarded as an upregulator of AO defences and a downregulator of ROS/free radical production under basal conditions and during exercise [98]. A recent study by Bouzid et al. [41] compared the effects of regular physical activity at high and moderate intensities on oxidative stress in older adults. The same authors concluded that both low and high physical exercise levels help to maintain better AO defences, namely, SOD, glutathione peroxidase, and glutathione reductase in older adults.

\section{Nutritional Antioxidant Intervention in the Elderly Subjected to Physical Exercise}

The intake of supplemental AOs in training elderly people should in principle abrogate the ROS-related negative effects elicited by muscle contraction without affecting the positive ones.

Despite this rationale, the effects of supplementation with AOs in training elderly people on physical performance and muscle conditions are controversial: for example, some studies using resveratrol, vitamin $\mathrm{C}$, and vitamin $\mathrm{E}$ showed protective actions resulting in the reduction of muscle damage [99-101], and supplementation with an AO mixture (vitamins $\mathrm{E}$ and $\mathrm{A}$, rutin, zinc, and selenium) plus leucine induced an anabolic response in an old muscle [102]. Conversely, other preclinical trials using vitamins $\mathrm{C}$ and $\mathrm{E}$ demonstrated that AO supplementation may abrogate the benefits of exercise, probably by silencing ROS signalling [103]. Ristow et al. [104] and Gomez-Cabrera et al. [105] have recently reported that $\mathrm{AO}$ supplementation can decrease training efficiency and prevent exercise-induced mitochondrial biogenesis in healthy humans. Furthermore, a recent study showed no effects of vitamins $\mathrm{C}$ and $\mathrm{E}$ supplementation on muscle function in response to exerciseinduced adaptation [106].

Another study dealt with $\mathrm{N}$-acetyl-cysteine administration aimed at fostering reduced glutathione availability during an 8-day period after eccentric exercise-induced muscle damage. In this study, it has been shown that, although redox status alterations attenuate oxidative damage and inflammation, they may delay muscle long-term recovery by interfering with intracellular signalling pathways [107].

Moreover, protein supplementation (e.g., whey and soy proteins and isoflavone-enriched soy proteins) has been proposed as a new AO strategy primarily because of its capacity to enhance the availability of reduced glutathione and the activity of the corresponding AO enzyme system. However, there is still a lack of information about the anabolic potential of dietary protein intake and protein supplementation in elderly people with increased systemic inflammation [108].

On the whole, AO supplements may optimize the training effects by protecting against exercise-induced ROS overproduction, but on the other hand, overdosed supplementation may blunt training beneficial adaptive effects.

However, it is important to note that these studies have been conducted using mainly vitamins $\mathrm{C}$ and $\mathrm{E}$ and results have been generally extended to the broader category of AOs. This term represents a rough simplification that can be misleading, since individual AOs differ in their mechanisms of action, redox affinity, bioavailability, tissue kinetic, intracellular distribution, dose dependence, and additional properties. Moreover, conclusions referring to a young and healthy human population should not be directly applied to the elderly population characterized by a significant impairment of redox balance underlying age-related muscle modifications and impaired adaptive response to exercise training.

In the same direction, Jackson competently and thoughtfully commented: "the combination of physiological and pathological roles of ROS imply that interventions based on a simple suppression of ROS activities through use of nonspecific AOs are unlikely to retard or improve the agerelated declines in muscle mass and function" [109]. Hence, the equation "more AOs - less muscle aging" is not an automatic truth and indeed, with respect to the 
prevention of sarcopenia, the question of whether supplementation with AOs is positive should be better addressed, with a particular focus on the possible broader biological properties of selected AOs.

\section{Creatine, New Perspectives from the Past}

$\mathrm{Cr}$ is among the most studied and long known molecules in modern and contemporary biology. Since its discovery, more than 150 years ago by Michel Chevreul, thousands of studies dissected and identified its central role in cellular energetics as the substrate for creatine kinases. According to its ergogenic function, the bulk of body $\mathrm{Cr}$ and $\mathrm{Cr}$ phosphate (CrP) is concentrated in skeletal muscles; body stores of $\mathrm{Cr}$ are maintained physiologically by nutritional intake through meat and fish consumption and endogenous biosynthesis [110]; and oral Cr supplementation further increases plasma $\mathrm{Cr}$ levels and intramuscular $\mathrm{Cr} / \mathrm{CrP}$ content in young, adult [110], and elderly people [111].

Today, Cr has a strong reputation as a safe nutritional supplement promoting a number of health benefits not limited to sport practitioners [112]. This notion has been recently strengthened by the official Position of the International Society of Sports Nutrition [113], which also ruled out the concerns on its possible renal toxicity.

In particular, $\mathrm{Cr}$, along with positively affecting muscle mass and performance [114-116], has been shown to favour myogenesis in normal and adverse conditions [117], to increase the expression level of specific muscle regulatory factors [118-121], to exert a trophic action on muscle cells [114], and to exert mild AO $[122,123]$ and antiinflammatory $[124,125]$ activity. Thus, a new concept of a Cr biochemical and physiological role has emerged pointing to its multiple, not only ergogenic, effects $[112,116,126]$. In this light, $\mathrm{Cr}$ can be regarded as a nutritional supplement fulfilling a number of requisites which might be important in delaying the onset and the progression of sarcopenia $[127,128]$. In this section, a summary of the multiple effects caused by $\mathrm{Cr}$ will be discussed.

The first evidence for an "AO-like" activity of $\mathrm{Cr}$ was reported by Matthews et al. [129] showing that oral $\mathrm{Cr}$, in analogy with established AOs such as $\mathrm{N}$-acetylcysteine, attenuated the hydroxyl radical and peroxynitrite generation in nitropropionic acid-intoxicated rats (an animal model of Huntington's disease) and prevented brain damages. The first report of the direct $\mathrm{AO}$ activity of $\mathrm{Cr}$ was provided by Lawler et al. [122] in an acellular setting (where Cr showed its ability to scavenge $\mathrm{ABTS}^{+}, \mathrm{O}_{2} \bullet^{-}$, and $\mathrm{OONO}^{-}$) and by Sestili et al. [123] in different mammalian cell lines challenged with a panel of oxidative stressors $\left(\mathrm{H}_{2} \mathrm{O}_{2}\right.$, t-butylhydroperoxide, and peroxynitrite). In this study, intracellular, but not extracellular, $\mathrm{Cr}$ at nutritionally attainable concentrations was mildly but significantly cytoprotective towards the three toxic species [123].

Since then, many authors reported that $\mathrm{Cr}$ exerts direct and indirect $\mathrm{AO}$ effects in different in vitro and in vivo experimental settings/conditions in which oxidative stress takes place. For example, in vitro settings showed protection from the exposure to $\mathrm{H}_{2} \mathrm{O}_{2}$, t-butyl-hydroperoxide, and peroxinitrite $[122,123,130]$, from oxidative damage to mtDNA [130-132] and RNA [133], from $\mathrm{H}_{2} \mathrm{O}_{2}$-induced arrest of myogenesis [117, 121], from UV rays damage $[131,132]$, and from glutamate-induced nitrosative and oxidative stress [134]. Animal studies showed that supplemental $\mathrm{Cr}$ protects from the toxicity of nitropropionate [129], of the mitochondrial electron transport inhibitor rotenone via direct AO activity [135], and of the proconvulsant drug pentylenetetrazole [136] and also demonstrated that $\mathrm{Cr}$ ameliorates the $\mathrm{AO}$ reservation against oxidative stress in exercise-trained ovariectomized hamsters [137], decreases ROS content with no changes in expression and activity of AO enzymes in rat skeletal muscle after 6 days supplementation [138], and reduces lipid peroxidation markers in exercising rats fed for 26 days with a Cr-enriched diet [139]. Human studies showed significantly lower accumulation of urinary $8-\mathrm{OHdG}$ and plasma malondialdehyde in trained adults after 1 week of Cr supplementation [140, 141], limited short-term oxidative insults after the Wingate test (1 week $\mathrm{Cr}$ supplementation) [142], and reduced oxidative stress in a steady-state test at $75 \% \mathrm{VO}_{2}(\max )$ after 5 days supplementation [143].

The mechanisms responsible for the AO activity of $\mathrm{Cr}$ are complex and have been extensively reviewed elsewhere $[116,144]$. These mechanisms do include not only direct but also indirect interactions. With regard to the latter, for example, $\mathrm{Cr}$ induces peroxiredoxin- 4 and thioredoxin-dependent peroxide reductases, two important $\mathrm{AO}$ enzymes located in the cytoplasm and mitochondria, respectively [145], and in addition, the same thioredoxin and peroxiredoxin system could benefit from the increased NADPH resynthesis due to the Cr-induced higher ATP availability [114, 116, 126, 146]; $\mathrm{Cr}$ has been shown to activate AMPK which in turn might promote cellular adaptive responses aimed at overcoming oxidative stress [117, 147, 148]; supplemental Cr may increase intracellular levels of arginine, which also can act as an AO [149]. Thus, the mild AO activity of $\mathrm{Cr}$ is likely to result from the superposition of multiple mechanisms.

Interestingly, the protective activity of $\mathrm{Cr}$ against acute oxidative stress, in spite of a scavenging potency lower than that of established AOs [122], proved to be better as compared to the latter in specific conditions [117, 121]. For instance, with regard to cultured muscle cell settings (C2C12 cells), a comparative study between the protective activity of Cr versus the reference AOs Trolox [150] or Nacetyl-cysteine [146] toward the cytotoxicity and the myogenic arrest caused by $\mathrm{H}_{2} \mathrm{O}_{2}$ showed that while $\mathrm{Cr}$ significantly attenuated both the toxic responses, the two reference AOs were not capable to prevent the latter. Such findings imply that in order to counteract specific adverse situations caused or exacerbated by oxidative stress, the "generic" capacity of acting as an AO might not be sufficient. Indeed, $\mathrm{Cr}$, beyond acting as a mild $\mathrm{AO}$, has other peculiar features which concur to muscle cell rescue as discussed below.

A prominent and qualifying feature of $\mathrm{Cr}$ is its particular tropism for skeletal muscle, where the bulk of body $\mathrm{Cr}$ is actively stored up to $30 \mathrm{mM}$ [3]: this very high, tissuespecific concentration might selectively enhance its $\mathrm{AO}$ activity in the muscle compartment. 
Furthermore, Cr shuttles energy from the site of production (mitochondria) to the site of consumption (cytoplasm) [116]. As a consequence, the particularly high gradient of $\mathrm{Cr}$ in mitochondria and across the mitochondrial membranes is likely to focus its activities in this critical subcellular compartment (see also above). Indeed, according to the mitochondrial theory of aging, a vicious circle (see Section 1) entailing the overgeneration of ROS by the MRC and damage to both mitochondrial and cellular structures leads to defective mitochondrial respiration and further increase in mitochondrial ROS production and oxidative damage [109]. ROS damage to mitochondria deteriorates their functionality, integrity, and networking, which represent fundamental requisites for muscle differentiation [117, 151-161] whose imbalance is associated with muscle decline conditions such as sarcopenia [162]. As stated above and in line with this mitochondrially oriented activity, $\mathrm{Cr}$ increases the content of mitochondrial thioredoxin reductase, an important $\mathrm{AO}$ enzyme, in myotube cultures [145].

According to this peculiar mitochondrial tropism, we recently demonstrated that the addition of $\mathrm{Cr}$ to $\mathrm{H}_{2} \mathrm{O}_{2}$-injured differentiating $\mathrm{C} 2 \mathrm{C} 12$ cells prevented the collapse of their mitochondria, attenuated the level of CL peroxidation, restored the respiration capacity, and prevented the fragmentation of the mitochondrial networks [117]. Cr was also found to increase mitochondrial mass and, accordingly, to stimulate the transcription level of PGC- $1 \alpha,[163,164]$, in both control and $\mathrm{H}_{2} \mathrm{O}_{2}$-injured differentiating $\mathrm{C} 2 \mathrm{C} 12$ cells. Finally, in the same cells and conditions and according to previous reports [148], Cr per se caused an increased phosphorylation of AMPK which, along with the increased CrP and ATP levels found in supplemented cells, concurs to a better handling of cellular energy to overcome critical situations $[117,121]$.

With regard to this last concept, it is worth considering that the most authentic, unique feature differentiating $\mathrm{Cr}$ from generic AOs is obviously its role in cellular energetics. Cr improves cellular energy state (CrP/ATP ratio), facilitates intracellular energy transport through the $\mathrm{CrP}$ circuit, and enhances the overall $\mathrm{CrP}$ pool [116]. Increased $\mathrm{CrP}$ levels can be utilized by $\mathrm{Cr}$ kinase to transphosphorylate ADP to ATP for various ATP-dependent processes, including those required for muscle contraction [116]. In addition, better CrP/ATP ratios improve the cellular calcium handling and homeostasis and maintain an adequate MRC activity thus preventing ROS leakage [116]. Indeed, the ATP highly consuming calcium pump of sarcoplasmic reticulum works efficiently as long as a high local ATP/ADP ratio is maintained by the action of $\mathrm{Cr}$ kinase [116]. In the $\mathrm{H}_{2} \mathrm{O}_{2}$ cytotoxicity setting described above, for example, this might ameliorate the handling of intracellular calcium [165] and help the preserving of the mitochondrial calcium signals, thus favouring myoblast differentiation even in the course of oxidative stress [117].

Cr protects $\mathrm{mtDNA}$ from the oxidative damage caused by $\mathrm{H}_{2} \mathrm{O}_{2}$ in HUVECs [130] or repeated UV irradiation in human fibroblasts [131], through mechanisms involving both $\mathrm{AO}$ effects and normalization of cells' energy status. These effects might be responsible for the $\mathrm{Cr}$-associated prevention of mtDNA loss caused by $\mathrm{H}_{2} \mathrm{O}_{2}$ in differentiating myoblasts [117]. Notably, the accumulation of mtDNA mutations is among the causative factors of sarcopenia [166].

Moreover, Cr stabilizes and prevents the opening of the mitochondrial permeability transition pore complex caused by a variety of adverse conditions, thus decreasing mitochondrial apoptotic susceptibility and cell death [167].

Hence, $\mathrm{Cr}$ ameliorates cellular energy status and at the same time protects the sites of energy production, that is, mitochondria, from ROS which would otherwise cause severe energy failure and cell death [167].

The last but not secondary distinctive feature of $\mathrm{Cr}$ as compared to generic AOs is its anabolic activity on skeletal muscle. This property has been documented since the " $70 \mathrm{~s}$ of the past century and has been demonstrated in a variety of in vitro $[120,168,169]$ as well as ex vivo animal studies [168] or human studies [170-173]. Human studies involved training healthy adults [171], rehabilitating adults [170] or sedentary adults [172], and training [173] elderly. There is a general consensus on the fact that $\mathrm{Cr}$-induced muscle anabolism depends mainly on its capacity to stimulate the mRNA expression of muscle regulatory factors, namely, Myo-D, Myf-5, MRF-4, and myogenin, and of IGF-1 [120] and to repress that of myostatin [169]. Other authors [174-177] reported positive effects of $\mathrm{Cr}$ supplementation on muscle mass and strength of exercising elderly and focused on the importance of the timing of $\mathrm{Cr}$ intakes, namely, pre- versus postexercise, to achieve better outcomes, postexercise intake being the most effective.

Given these premises, $\mathrm{Cr}$ could then represent a valuable dietary supplement to prevent muscle aging and sarcopenia. Interestingly, some of the effects elicited by supplementary $\mathrm{Cr}$ overlap with, and may reinforce, the positive ones induced by physical exercise (i.e., higher expression of PGC- $1 \alpha$ and of muscle regulatory factors), and others (i.e., the ergogenic ones) do support physical training: on the whole, these peculiar traits are likely to give rise to a positive loop that, with regard to sarcopenia, suggests that supplementary $\mathrm{Cr}$ may positively interact with physical exercise. Indeed, recent studies on older adults and elderly people actually support this notion. Two distinct trials on community-dwelling older Canadian adults $[178,179]$ showed overall greater improvements in strength and higher gains in fat-free mass in $\mathrm{Cr}$ supplemented participants, when compared with the placebo groups. A meta-analysis [180] of data from 357 older adults found enhanced benefits (in terms of lean mass, strength, and bone mass) of exercise training when combined with $\mathrm{Cr}$ supplementation. Another study showed that the addition of $\mathrm{Cr}$ enhances isometric strength and body composition improvements following strength exercise training in older adults [178]. A well-designed and more recent trial on 32 healthy, nonathletic men and women aged 60-80 years showed that three months of low-dose $\mathrm{Cr}$ supplementation associated with resistance training resulted in significant increases in lean mass [181]. In particular, unlike the placebo/resistance training group, the Cr/resistance training group (initial body, lean, android, and gynoid fat masses of $68.1,38.3,39.6$, and $45.1 \mathrm{~kg}$, resp.) showed a significant increase in muscle mass $(+1.79 \mathrm{~kg})$, a significant 
decrease in android and gynoid fat $(-1.02 \mathrm{~kg}$ and $-1.56 \mathrm{~kg}$ resp.), and a tendency to decrease body fat $(-1.22 \mathrm{~kg})$.

On the whole, the recognition of its pleiotropic nature, along with the encouraging outcomes of the trials on elderly people $[127,128,173,176,178,180-183]$, provides a strong rationale for considering and reappraising $\mathrm{Cr}$ as a valuable and safe supplement to counteract sarcopenia. As a final clue in support of this idea, it is worth noting that a study on mice demonstrated that $\mathrm{Cr}$ exerts a fair antiaging effect, since its chronic supplementation increases lifespan, improves health, and attenuates changes in biochemical and genetic markers associated with aging [184].

\section{Coenzyme Q10 as Ergogenic and AO Mitochondrial Nutrient}

$\mathrm{CoQ}$ is an endogenous isoprenylated quinone isolated for the first time in 1957 by Crane et al. from beef heart mitochondria [185]. Isoprenylation is responsible for the high lipophilic nature of this molecule that is ubiquitous in biological membranes, and therefore, it is also known as ubiquinone. The analysis of the literature shows that ubiquinone homologs are highly represented in various organisms from monera to vertebrates although they may differ in the number of isoprenoid units, in particular, ubiquinone in humans is present in the form of CoQ10, the homolog with ten isoprenoid units [186]. From a chemical point of view, CoQ10 is able to act as an electron and proton shuttle following two-electron redox reaction and reversible conversion from the oxidized form (ubiquinone) to the reduced form (ubiquinol). The redox properties of ubiquinone underlie its major biological functions, namely, to act both as an electron carrier intermediate in the mitochondrial respiratory chain and as a phenolic AO in the lipid environment. These two characteristics strongly link CoQ10 biochemistry to mitochondrial bioenergetics [187] and differentiate its role from other low molecular weight AOs. In fact, while CoQ is ubiquitous in all biological membranes (e.g., cellular organelles and plasma membrane) and in lipoproteins, it is of particular relevance to the inner mitochondrial membrane where the oxidative phosphorylation occurs and, consequently, to tissues characterized by high respiratory demand and energy turnover such as cardiac and skeletal muscle tissues [188].

Ubiquinol is a potent reducing agent that can interrupt the initiation of lipid peroxidation or also break the chain reactions by reacting with lipid peroxide radicals [189].

Ubiquinol acts mainly as a chain-breaking antioxidant in the membrane, reacting with carbon- and oxygen-centered radicals while its reactivity toward hydroperoxyl radicals is limited and much slower than that of tocopherol [190] one of the most potent exogenous antioxidants. Nonetheless, ubiquinol is more efficient against peroxidation of LDL (lowdensity lipoproteins) than $\alpha$-tocopherol [191] that on a molar basis represents by far the major antioxidant in lipoproteins.

Ubiquinol and tocopherol interplay synergistically with important consequences in relation to the antioxidant activities of both molecules: ubiquinol regenerates tocopherol from oxidized tocopheryl radical, thus protecting the lipid environment from oxidation [188]; moreover, ubiquinol when compared with $\alpha$-tocopherol has a higher reactivity toward both galvinoxyl and peroxyl radicals, since ubiquinol has two active hydrogens that react with oxygen radicals whereas $\alpha$-tocopherol has only one. The reaction leads to the production of semiquinone radical which subsequently reacts with another radical $\mathrm{X}$ to give ubiquinone. In the case of peroxyl radicals, the steady state concentration of these radicals is usually low. Under these conditions, the life of semiquinone radical is longer and it has more chance to react with oxygen to give ubiquinone and hydroperoxyl radical. In this condition, hydroperoxyl radical may react with lipid to induce a lipid peroxidation, which results in the reduction of induction period or increase in the rate of lipid peroxidation. Under these conditions, ubiquinol does not act as an antioxidant [192].

However, in physiological conditions, tocopherol abundance in membranes scavenges hydroperoxyl radical and suppresses autoxidation of ubiquinol exerting a potent combined antioxidant effect $[193,194]$. It is worth noting that, in mitochondria, the reduced form of CoQ is regenerated by the respiratory chain. In fact, both ubiquinol and the ubisemiquinone radicals can react with complex III and be suitably oxidized/reduced at the Qo and Qi sites of the enzyme. In addition, ubiquinone can be fully reduced by complex I, complex II, and other dehydrogenases of the inner mitochondrial membrane.

In the MRC, electrons donated from NAD- and FADdependent dehydrogenases funnel into $\mathrm{CoQ}$ as a common acceptor that in turn feeds into the cytochrome system $[195,196]$. Growing evidence describes in detail the structure and function of the "core" respiratory complexes (i.e., complexes I, II, III, and IV) while several auxiliary enzymes have been also described to reduce ubiquinone [197] or to deliver electrons directly to oxygen (i.e., alternative ubiquinol oxidase) by bypassing complexes III and IV (see [198, 199]) of the respiratory enzymes [198]. Most certainly, ubiquinone/ubiquinol molecules bound to respiratory complexes coexist with a mobile pool of molecules in the lipid bilayer of the inner mitochondrial membrane. Notably, their physiological concentration is close to the $\mathrm{Km}$ (concentration yielding half-maximal velocity) of the respiratory enzyme CoQ [198]. This fact implies that even slight variations in the concentration of mitochondrial CoQ result in dramatic changes in the respiratory rate, further stressing the biological relevance of subliminal deficit in the biosynthesis and providing a rationale for the use of exogenous $\mathrm{CoQ}$ as an ergogenic supplement (see below for further discussion).

CoQ10 synthesis in eukaryotes comprises at least ten enzymatic reactions in large part along the mevalonate pathway where isoprenoid units are formed [200]. Although in physiological conditions the organism produces sufficient amount of CoQ10, a small proportion $(3-5 \mathrm{mg} /$ day) is also introduced through the diet, in particular, through meat and fish consumption [201]. Dietary CoQ10 is absorbed in the plasma, where it is vehiculated by lipoproteins and delivered to tissues. In pathological conditions, primary and secondary deficits in CoQ10 synthesis lead to severe mitochondrial impairment and are associated with different 
neurologic and muscular degenerative disorders [202-204]; moreover, pathological conditions associated with enhanced oxidative stress might result in an altered CoQ10 status [205]. Also, within physiological conditions, the CoQ10 status might be influenced in terms both of concentration and oxidative state by different factors including nutrition [201], physical activity [206], drug use [207-209], and aging [210-212]. In particular, in relation to the topic of this review, physical exercise is associated with a decreased CoQ10 plasma level, suggesting a higher tissue demand during training [206]. Moreover, CoQ10 synthesis in humans progressively declines after 20 years of age [210] as well as the activities of the reductases responsible for CoQ activation to its $\mathrm{AO}$ form, ubiquinol.

Accordingly, the abovementioned CoQ10 deprivation conditions are known to promote susceptibility of mitochondria to oxidative damage, as in the case of muscle toxicity caused by statins [207-209] commonly prescribed to elderly people. Notably, the entity of statins' adverse effects depends on multiple factors including genetic background $[213,214]$ and physical activity $[215,216]$ stressing the fact that even subliminal deficit in CoQ endogenous synthesis could significantly influence individual tolerance threshold. Taking into account that CoQ10 endogenous biosynthesis is also influenced by the mentioned extrinsic and intrinsic factors, notably, age and physical exercise, it is clear that muscle CoQ10 status deserves particular attention in the frame of age-related sarcopenia development.

According to the figures discussed so far, CoQ10 has been used over the last three decades as a nutritional supplement with ergogenic and $\mathrm{AO}$ activities to support mitochondrial bioenergetics and counteract oxidative stress in a wide range of clinical conditions [217-221].

However, the proven existence of respiratory SCs poses the question whether their role is compatible with the interpretation on bioenergetic grounds of the beneficial effect of orally administered exogenous CoQ10. In theory, by considering $\mathrm{CoQ}$ channeling within the SC, we might expect that ubiquinone content can be imposed by the amount of SC itself and therefore very much lower than the physiological CoQ10 concentration in the membrane. On the contrary, a careful reasoning based on the notion that bound CoQ within the SC is in chemical equilibrium with $\mathrm{CoQ}$ in the membrane pool supports the idea that even a slight decrease of endogenous ubiquinone content is sufficient to dissociate part of the quinone molecules from the SC. This consideration is also in line with the recently unveiled architecture of SC showing that the CoQ-binding sites of complex I and complex III are $10 \mathrm{~nm}$ apart and face a lipid microdomain that is open to the membrane [10]. In such a situation, it is likely that the function of the large amount of CoQ in natural mitochondrial membranes is to maintain the proper quinone compartmentation within the SC unit when it is formed: therefore, CoQ10 supplementation might also ameliorate a deficient respiratory activity.

Both bioenergetic and $\mathrm{AO}$ activities concur to optimize mitochondrial functionality and prevent oxidative damage that could fuel, through a vicious circle, mitochondrial ROS formation. Moreover, newly investigated action mechanisms of CoQ10, besides its free radical scavenging property, include the following: (1) a direct modulation of mitochondrial permeability transition pore (PTP); (2) anti-inflammatory activity; and (3) regulation of gene transcription. These mechanisms will be discussed in relation to their relevance to the physiology and biochemistry of the aging muscle and the potential role of CoQ10 in the prevention of sarcopenia.

PTP is a high-conductance protein channel located in the inner mitochondrial membrane [222]. In response to stress signals, mitochondrial depolarization causes the opening of the pore thus leading to increased permeability of the mitochondrial membranes to small molecules ( $<1500$ daltons) in the intermembrane space, such as cytochrome c. The release of these factors in the cytoplasm is able to activate the process of cell death (apoptosis). PTP transition might be the result of acute injuries, such as hypoxia, insult in heart attack, or stroke, or might be the consequence of mitochondrial dysfunction leading to alterations of mitochondrial membrane potential and mobilization of $\mathrm{Ca}^{2+}$ stores.

While apoptotic pathways are required for normal cell turnover and tissue homeostasis, misregulation of programmed cell death is increasingly implicated in aging and aging-related diseases [223]. Indeed, in the aging muscle, apoptosis is known to be involved in muscle fiber atrophy and loss of myofibers, two common features of sarcopenia [224]. The onset of this degenerative process seems to stem from the accumulation of senescence-related mutations in mtDNA [130, 225-227], the concomitant development of MRC abnormalities triggering apoptotic and, ultimately, necrotic events. Moreover, sporadic denervation occurring in the elderly may also exacerbate these deleterious events [228]. Quinones have been shown to exert a direct effect on PTP [229] through a common binding site rather than through redox reactions. Occupancy of this site can modulate the PTP open-closed transitions, possibly through secondary changes of the $\mathrm{Ca}^{2+}$-binding affinity for the pore [230]. Evidences that CoQ10 inhibits the opening of the pore besides reducing the concentration of superoxide anion were obtained using a model of amyloid/oxygen glucose deprivation-induced neuronal excitotoxicity [231], in amitriptyline toxicity [232] and in ischemia and reperfusion in the heart [233]. These reports do not provide an evidence of a direct modulation of the pore by CoQ10: thus, this effect could be simply mediated by its $\mathrm{AO}$ capacity.

Concerning the CoQ10 anti-inflammatory effect, the recent literature suggests that it acts through the inhibition of NF- $\kappa \mathrm{B}$ nuclear translocation, preventing low-grade inflammation characteristic of inflammaging $[60,234]$.

The aging cell is characterized by a chronic proinflammatory state where NF- $\kappa \mathrm{B}$ acts as a key regulator of genes that encode cytokines, cytokine receptors, and cell-adhesion molecules [235-239]. Interestingly, CoQ10 supplementation has been shown to influence the expression of proinflammatory NF- $\kappa \mathrm{B}$ and stress-related gene activation, by modulating the expression of miR-146a both in LPS-stimulated monocyte $[239,240]$ and in young and senescent endothelial cells.

Finally, CoQ10 has been shown to influence the expression of a wide set of genes [240-244]. Modulation of inflammation described above represents a clear example 


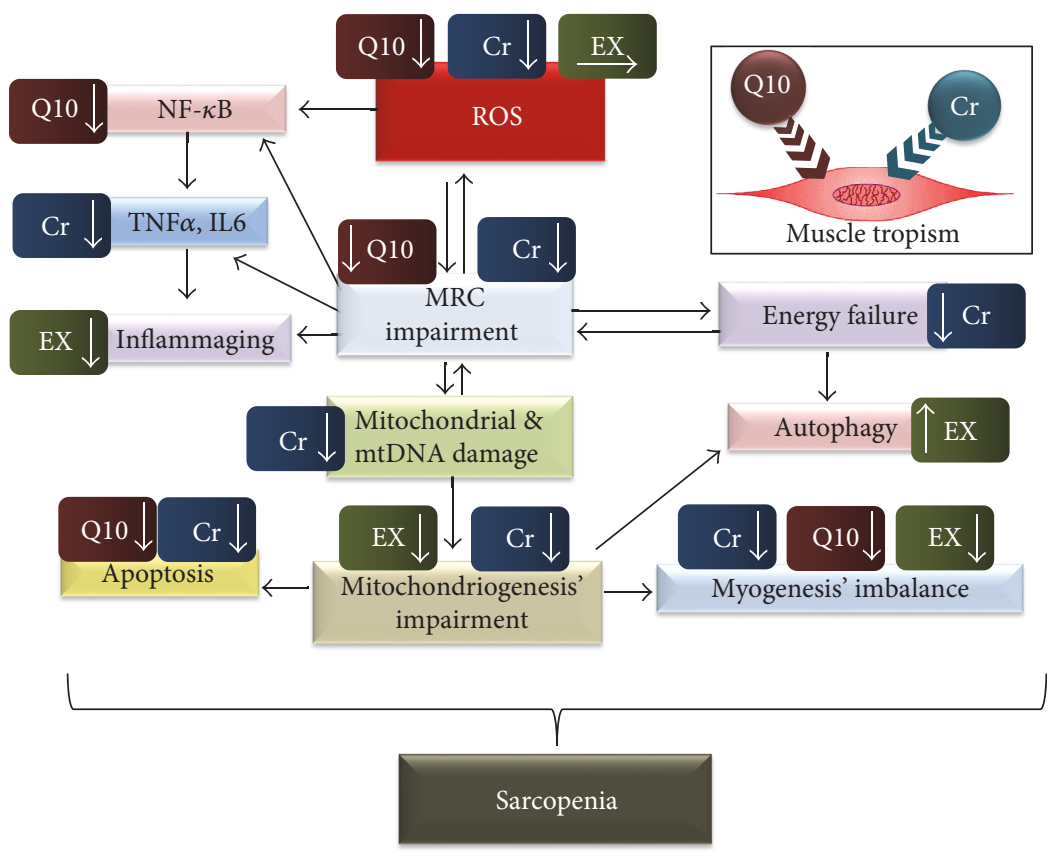

FIgURE 1: The role of ROS in the pathogenesis of sarcopenia and the multiple positive and converging effects promoted by Cr, CoQ10, or physical training. The sequences of relevant ROS-related pathogenetic events leading to sarcopenia are summarized in the flow chart, where the effects promoted by $\mathrm{Cr}$, CoQ10, or physical exercise (corresponding to the labels "Cr," "Q10," and "EX" in the figure, resp.) are also illustrated. The types of the modulations caused by Cr, CoQ10, and EX are symbolized according to the following scheme: labels with the arrow pointing down = decrease, arrow pointing up=increase, and arrow pointing right=hormetic effect. The inset in the upper rightmost of the figure emphasizes the high accumulation of $\mathrm{Cr}$ and CoQ10 in skeletal muscles.

where CoQ10 is able to influence the nuclear translocation of $\mathrm{NF}-\kappa \mathrm{B}$. This is probably achieved through the direct AO effect of ubiquinol similarly to other AOs [245], although a direct modulation of regulatory miRNAs cannot be ruled out. Moreover, differently from other AOs, a controlled prooxidant activity at the level of the MRC might contribute to the release of potent inducers of gene expression, such as $\mathrm{H}_{2} \mathrm{O}_{2}$. In particular, Linnane et al. [243] hypothesized that global gene expression regulation induced by CoQ10 in skeletal muscle is indeed achieved via superoxide formation with $\mathrm{H}_{2} \mathrm{O}_{2}$ as a second messenger to the nucleus. In a randomized controlled clinical study, human test subjects about to undergo hip replacement were given $300 \mathrm{mg}$ CoQ10/die or placebo for 25-30 days before surgery: microarray gene expression patterns and muscle fiber type profiles from vastus lateralis samples showed a consistent CoQ10dependent regulation of 115 genes with 47 genes upregulated and 68 downregulated in the CoQ10-treated subjects [246]. Moreover, a significant difference in the number of mitochondria-rich type I fibers was observed between placebo and CoQ10 patients. CoQ10-treated samples were also characterized by a higher proportion of type II fibers. These fibers have fewer mitochondria per cell and are more glycolytic with respect to energy requirements; they are involved in fast contractions and their proportion decreases with age [22]. The same authors concluded that the patients receiving CoQ10 have an altered fiber type composition more reflective of younger muscle than the group receiving the placebo.

Coenzyme Q10, in light of the abovementioned properties and biological effects and besides its long standing use in different clinical fields, has attracted considerable interest as a safe food supplement in human nutrition as well as specialised sport nutrition. Clinical trials supporting this application include animal studies [247] where senescenceaccelerated mice supplemented up to 10 months with ubiquinol showed improved exercise capacity, measured as time of run on a treadmill until exhaustion; moreover, CoQ10 supplementation was shown to lower exhaustive exerciseinduced muscular injury in rats by enhancing stabilization of muscle cell membrane [248]. In humans, trials have been conducted both with the use of ubiquinone and more recently with ubiquinol. In general, data have shown that supplementation in healthy trained individuals produces an increase in oxygen uptake, improvement in cardiac parameters, and enhanced resistance, as validated also by means of randomized crossover studies [249-251]. CoQ supplementation was also shown to be effective in reducing exerciseinduced oxidative damage [221] and muscular injury in humans [221, 252].

\section{Conclusions}

The significant socioeconomic costs of musculoskeletal aging, in an expanding elderly population, have emphasized the need to develop effective, safe, and costless interventions to prevent and/or delay the progression of sarcopenia: to this aim, a likely candidate is the association of exercise training with AOs.

However, as we have extensively discussed, a profound reappraisal of the role of AOs in preventing sarcopenia is needed. Indeed, the agents categorized under the generic 
heading of "AO," that is, capable of broadly and simply blocking ROS, have not provided until now clear evidence for their benefits. On the contrary, dietary AOs characterized by additive features, such as positive muscle tropism and multiple converging actions, might reveal a much more therapeutically profitable effect.

In this light, we believe that both $\mathrm{Cr}$ and CoQ10 can be considered as "muscle-specific pleiotropic AOs" capable of positively, if not synergistically, interacting with physical training to delay the onset and progression of sarcopenia (Figure 1). This topic requires further investigation, but it could pave the way for a better understanding of the mechanisms of skeletal muscle adaptation and plasticity and provide novel therapeutic targets to "reset" age-associated muscle loss.

\section{Conflicts of Interest}

The authors declare that there is no conflict of interests.

\section{References}

[1] J. E. Morley, R. N. Baumgartner, R. Roubenoff, J. Mayer, and K. S. Nair, "Sarcopenia," The Journal of Laboratory and Clinical Medicine, vol. 137, no. 4, pp. 231-243, 2001.

[2] P. M. Cawthon, L. M. Marshall, Y. Michael et al., "Frailty in older men: prevalence, progression, and relationship with mortality," Journal of the American Geriatrics Society, vol. 55, no. 8, pp. 1216-1223, 2007.

[3] P. Sousa-Victor, L. Garcia-Prat, A. L. Serrano, E. Perdiguero, and P. Muñoz-Cánoves, "Muscle stem cell aging: regulation and rejuvenation," Trends in Endocrinology and Metabolism, vol. 26, no. 6, pp. 287-296, 2015.

[4] S. I. Liochev, "Reflections on the theories of aging, of oxidative stress, and of science in general. Is it time to abandon the free radical (oxidative stress) theory of aging?," Antioxidants \& Redox Signaling, vol. 23, no. 3, pp. 187-207, 2015.

[5] L. L. Ji, "Redox signaling in skeletal muscle: role of aging and exercise," Advances in Physiology Education, vol. 39, no. 4, pp. 352-359, 2015.

[6] B. Chabi, V. Ljubicic, K. J. Menzies, J. H. Huang, A. Saleem, and D. A. Hood, "Mitochondrial function and apoptotic susceptibility in aging skeletal muscle," Aging Cell, vol. 7, no. 1, pp. 2-12, 2008.

[7] L. A. Gomez and T. M. Hagen, "Age-related decline in mitochondrial bioenergetics: does supercomplex destabilization determine lower oxidative capacity and higher superoxide production?," Seminars in Cell \& Developmental Biology, vol. 23, no. 7, pp. 758-767, 2012.

[8] E. Maranzana, G. Barbero, A. I. Falasca, G. Lenaz, and M. L. Genova, "Mitochondrial respiratory supercomplex association limits production of reactive oxygen species from complex I," Antioxidants \& Redox Signaling, vol. 19, no. 13, pp. 1469-1480, 2013.

[9] K. Fiedorczuk, J. A. Letts, G. Degliesposti, K. Kaszuba, M. Skehel, and L. A. Sazanov, "Atomic structure of the entire mammalian mitochondrial complex I," Nature, vol. 538, no. 7625, pp. 406-410, 2016.

[10] J. A. Letts, K. Fiedorczuk, and L. A. Sazanov, "The architecture of respiratory supercomplexes," Nature, vol. 537, no. 7622, pp. 644-648, 2016.
[11] M. L. Genova and G. Lenaz, "The interplay between respiratory supercomplexes and ROS in aging," Antioxidants \& Redox Signaling, vol. 23, no. 3, pp. 208-238, 2015.

[12] J. Vina, C. Borras, K. M. Abdelaziz, R. Garcia-Valles, and M. C. Gomez-Cabrera, "The free radical theory of aging revisited: the cell signaling disruption theory of aging," Antioxidants \& Redox Signaling, vol. 19, no. 8, pp. 779-787, 2013.

[13] R. Buffenstein, Y. H. Edrey, T. Yang, and J. Mele, "The oxidative stress theory of aging: embattled or invincible? Insights from non-traditional model organisms," Age, vol. 30, no. 23, pp. 99-109, 2008.

[14] F. Scialo, A. Sriram, D. Fernandez-Ayala et al., "Mitochondrial ROS produced via reverse electron transport extend animal lifespan," Cell Metabolism, vol. 23, no. 4, pp. 725-734, 2016.

[15] N. Khansari, Y. Shakiba, and M. Mahmoudi, "Chronic inflammation and oxidative stress as a major cause of agerelated diseases and cancer," Recent Patents on Inflammation \& Allergy Drug Discovery, vol. 3, no. 1, pp. 73-80, 2009.

[16] J. A. Woods, K. R. Wilund, S. A. Martin, and B. M. Kistler, "Exercise, inflammation and aging," Aging and Diseases, vol. 3, no. 1, pp. 130-140, 2012.

[17] A. A. Moskalev, A. M. Aliper, Z. Smit-McBride, A. Buzdin, and A. Zhavoronkov, "Genetics and epigenetics of aging and longevity," Cell Cycle, vol. 13, no. 7, pp. 1063-1077, 2014.

[18] O. Matilainen, P. M. Quiròs, and J. Auwerx, "Mitochondria and epigenetics - crosstalk in homeostasis and stress," Trends in Cell Biology, vol. 27, no. 6, pp. 453-463, 2017.

[19] L. J. Greenlund and K. S. Nair, "Sarcopenia-consequences, mechanisms, and potential therapies," Mechanisms of Ageing and Development, vol. 124, no. 3, pp. 287-299, 2003.

[20] R. Rowiński, M. Kozakiewicz, K. Kędziora-Kornatowska, E. Hübner-Woźniak, and J. Kędziora, "Markers of oxidative stress and erythrocyte antioxidant enzyme activity in older men and women with differing physical activity," Experimental Gerontology, vol. 48, no. 11, pp. 1141-1146, 2013.

[21] N. Napoli, K. Shah, D. L. Waters, D. R. Sinacore, C. Qualls, and D. T. Villareal, "Effect of weight loss, exercise, or both on cognition and quality of life in obese older adults," The American Journal of Clinical Nutrition, vol. 100, no. 1, pp. 189-198, 2014.

[22] R. Nilwik, T. Snijders, M. Leenders et al., "The decline in skeletal muscle mass with aging is mainly attributed to a reduction in type II muscle fiber size," Experimental Gerontology, vol. 48, no. 5, pp. 492-498, 2013.

[23] I. G. Fatouros, A. Z. Jamurtas, V. Villiotou et al., "Oxidative stress responses in older men during endurance training and detraining," Medicine and Science in Sports and Exercise, vol. 36, no. 12, pp. 2065-2072, 2004.

[24] Z. Radak, Z. Bori, E. Koltai et al., "Age-dependent changes in 8-oxoguanine-DNA glycosylase activity are modulated by adaptive responses to physical exercise in human skeletal muscle," Free Radical Biology \& Medicine, vol. 51, no. 2, pp. 417-423, 2011.

[25] Z. Bori, Z. Zhao, E. Koltai et al., "The effects of aging, physical training, and a single bout of exercise on mitochondrial protein expression in human skeletal muscle," Experimental Gerontology, vol. 47, no. 6, pp. 417-424, 2012.

[26] R. T. Mankowski, S. D. Anton, T. W. Buford, and C. Leeuwenburgh, "Dietary antioxidants as modifiers of physiologic adaptations to exercise," Medicine and Science in Sports and Exercise, vol. 47, no. 9, pp. 1857-1868, 2015. 
[27] G. W. Heath, J. M. Hagberg, A. A. Ehsani, and J. O. Holloszy, "A physiological comparison of young and older endurance athletes," Journal of Applied Physiology: Respiratory, Environmental and Exercise Physiology, vol. 51, no. 3, pp. 634-640, 1981.

[28] W. R. Frontera, V. A. Hughes, K. J. Lutz, and W. J. Evans, “A cross-sectional study of muscle strength and mass in 45- to 78-yr-old men and women," Journal of Applied Physiology (Bethesda, Md: 1985), vol. 71, no. 2, pp. 644-650, 1991.

[29] M. R. Deschenes, "Effects of aging on muscle fibre type and size," Sports Medicine (Auckland, N Z), vol. 34, no. 12, pp. 809-824, 2004.

[30] A. A. Sayer, S. M. Robinson, H. P. Patel, T. Shavlakadze, C. Cooper, and M. D. Grounds, "New horizons in the pathogenesis, diagnosis and management of sarcopenia," Age and Ageing, vol. 42, no. 2, pp. 145-150, 2013.

[31] E. Marzetti, R. Calvani, M. Cesari et al., "Mitochondrial dysfunction and sarcopenia of aging: from signaling pathways to clinical trials," The International Journal of Biochemistry \& Cell Biology, vol. 45, no. 10, pp. 2288-2301, 2013.

[32] V. Ljubicic, A. M. Joseph, A. Saleem et al., "Transcriptional and post-transcriptional regulation of mitochondrial biogenesis in skeletal muscle: effects of exercise and aging," Biochimica et Biophysica Acta, vol. 1800, no. 3, pp. 223-234, 2010.

[33] R. Calvani, A. M. Joseph, P. J. Adhihetty et al., "Mitochondrial pathways in sarcopenia of aging and disuse muscle atrophy," Biological Chemistry, vol. 394, no. 3, pp. 393-414, 2013.

[34] G. Lenaz and M. L. Genova, "Structural and functional organization of the mitochondrial respiratory chain: a dynamic super-assembly," The International Journal of Biochemistry \& Cell Biology, vol. 41, no. 10, pp. 1750-1772, 2009.

[35] A. V. Lokhmatikov, N. Voskoboynikova, D. A. Cherepanov et al., "Impact of antioxidants on cardiolipin oxidation in liposomes: why mitochondrial cardiolipin serves as an apoptotic signal?," Oxidative Medicine and Cellular Longevity, vol. 2016, Article ID 8679469, 19 pages, 2016.

[36] G. Lenaz, G. Tioli, A. I. Falasca, and M. L. Genova, "Complex I function in mitochondrial supercomplexes," Biochimica et Biophysica Acta, vol. 1857, no. 7, pp. 991-1000, 2016.

[37] G. Lenaz, A. Baracca, G. Barbero et al., "Mitochondrial respiratory chain super-complex I-III in physiology and pathology," Biochimica et Biophysica Acta, vol. 1797, no. 6-7, pp. 633-640, 2010.

[38] F. Diaz, J. A. Enriquez, and C. T. Moraes, "Cells lacking Rieske iron-sulfur protein have a reactive oxygen species-associated decrease in respiratory complexes I and IV," Molecular and Cellular Biology, vol. 32, no. 2, pp. 415-429, 2012.

[39] F. Gonzalvez, M. D'Aurelio, M. Boutant et al., "Barth syndrome: cellular compensation of mitochondrial dysfunction and apoptosis inhibition due to changes in cardiolipin remodeling linked to tafazzin (TAZ) gene mutation," Biochimica et Biophysica Acta, vol. 1832, no. 8, pp. 1194-1206, 2013.

[40] B. Friguet, "Protein repair and degradation during aging," The Scientific World Journal, vol. 2, pp. 248-254, 2002.

[41] M. A. Bouzid, E. Filaire, A. Mc Call, and C. Fabre, "Radical oxygen species, exercise and aging: an update," Sports Medicine (Auckland, N Z), vol. 45, no. 9, pp. 1245-1261, 2015.

[42] Y. Collins, E. T. Chouchani, A. M. James, K. E. Menger, H. M. Cochemé, and M. P. Murphy, "Mitochondrial redox signalling at a glance," Journal of Cell Science, vol. 125, Part 4, pp. 801-806, 2012.
[43] B. D'Autreaux and M. B. Toledano, "ROS as signalling molecules: mechanisms that generate specificity in ROS homeostasis," Nature Reviews Molecular Cell Biology, vol. 8, no. 10, pp. 813-824, 2007.

[44] E. Barbieri and P. Sestili, "Reactive oxygen species in skeletal muscle signaling," Journal of Signal Transduction, vol. 2012, Article ID 982794, 17 pages, 2012.

[45] M. Meyer, H. L. Pahl, and P. A. Baeuerle, "Regulation of the transcription factors NF-kappa B and AP-1 by redox changes," Chemico-Biological Interactions, vol. 91, no. 2-3, pp. 91-100, 1994.

[46] R. G. Allen and M. Tresini, "Oxidative stress and gene regulation," Free Radical Biology \& Medicine, vol. 28, no. 3, pp. 463-499, 2000.

[47] Z. Wu, P. Puigserver, U. Andersson et al., "Mechanisms controlling mitochondrial biogenesis and respiration through the thermogenic coactivator PGC-1," Cell, vol. 98, no. 1, pp. 115-124, 1999.

[48] D. R. Bolster, N. Kubica, S. J. Crozier et al., "Immediate response of mammalian target of rapamycin (mTOR)-mediated signalling following acute resistance exercise in rat skeletal muscle," The Journal of Physiology, vol. 553, Part 1, pp. 213-220, 2003.

[49] L. Z. Zhou, A. P. Johnson, and T. A. Rando, "NF $\kappa$ B and AP-1 mediate transcriptional responses to oxidative stress in skeletal muscle cells," Free Radical Biology \& Medicine, vol. 31, no. 11, pp. 1405-1416, 2001.

[50] C. Handschin and B. M. Spiegelman, "Peroxisome proliferator-activated receptor $\gamma$ coactivator 1 coactivators, energy homeostasis, and metabolism," Endocrine Reviews, vol. 27, no. 7, pp. 728-735, 2006.

[51] R. C. Scarpulla, R. B. Vega, and D. P. Kelly, "Transcriptional integration of mitochondrial biogenesis," Trends in Endocrinology and Metabolism, vol. 23, no. 9, pp. 459-466, 2012.

[52] D. P. Kelly and R. C. Scarpulla, "Transcriptional regulatory circuits controlling mitochondrial biogenesis and function," Genes \& Development, vol. 18, no. 4, pp. 357-368, 2004.

[53] T. Wenz, S. G. Rossi, R. L. Rotundo, B. M. Spiegelman, and C. T. Moraes, "Increased muscle PGC- $1 \alpha$ expression protects from sarcopenia and metabolic disease during aging," Proceedings of the National Academy of Sciences of the United States of America, vol. 106, no. 48, pp. 20405-20410, 2009.

[54] A. Wagatsuma and K. SakumaMolecular mechanisms for age-associated mitochondrial deficiency in skeletal muscle," Journal of Aging Research, vol. 2012, Article ID 768304, 14 pages, 2012.

[55] J. Zhang, J. Kim, A. Alexander et al., "A tuberous sclerosis complex signalling node at the peroxisome regulates mTORC1 and autophagy in response to ROS," Nature Cell Biology, vol. 15, no. 10, pp. 1186-1196, 2013.

[56] H. G. Hambright, P. Meng, A. P. Kumar, and R. Ghosh, "Inhibition of PI3K/AKT/mTOR axis disrupts oxidative stress-mediated survival of melanoma cells," Oncotarget, vol. 6, no. 9, pp. 7195-7208, 2015.

[57] C. M. Hung, L. Garcia-Haro, C. A. Sparks, and D. A. Guertin, "mTOR-dependent cell survival mechanisms," Cold Spring Harbor Perspectives in Biology, vol. 4, no. 12, 2012.

[58] D. P. Jones and Y. M. Go, "Redox compartmentalization and cellular stress,” Diabetes, Obesity \& Metabolism, vol. 12, Supplement 2, pp. 116-125, 2010. 
[59] M. J. Morgan and Z. G. Liu, "Crosstalk of reactive oxygen species and NF-kB signaling," Cell Research, vol. 21, no. 1, pp. 103-115, 2011.

[60] C. Franceschi, M. Bonafè, S. Valensin et al., "Inflamm-aging. An evolutionary perspective on immunosenescence," Annals of the New York Academy of Sciences, vol. 908, pp. 244-254, 2000.

[61] S. J. Meng and L. J. Yu, "Oxidative stress, molecular inflammation and sarcopenia," International Journal of Molecular Sciences, vol. 11, no. 4, pp. 1509-1526, 2010.

[62] M. Guescini, B. Canonico, F. Lucertini et al., "Muscle releases alpha-sarcoglycan positive extracellular vesicles carrying miRNAs in the bloodstream," PLoS One, vol. 10, no. 5, article e0125094, 2015.

[63] J. M. Dhahbi, "Circulating small noncoding RNAs as biomarkers of aging," Ageing Research Reviews, vol. 17, pp. 86-98, 2014.

[64] P. Srikanthan and A. S. Karlamangla, "Muscle mass index as a predictor of longevity in older adults," The American Journal of Medicine, vol. 127, no. 6, pp. 547-553, 2014.

[65] C. Handschin and B. M. Spiegelman, "The role of exercise and PGC1 $\alpha$ in inflammation and chronic disease," Nature, vol. 454, no. 7203, pp. 463-469, 2008.

[66] A. R. Coggan, R. J. Spina, D. S. King et al., "Skeletal muscle adaptations to endurance training in 60- to 70-yr-old men and women," Journal of Applied Physiology (Bethesda, Md.:1985), vol. 72, no. 5, pp. 1780-1786, 1992.

[67] H. Klitgaard, M. Mantoni, S. Schiaffino et al., "Function, morphology and protein expression of ageing skeletal muscle: a cross-sectional study of elderly men with different training backgrounds," Acta Physiologica Scandinavica, vol. 140, no. 1, pp. 41-54, 1990.

[68] M. Rasmussen, J. R. Zierath, and R. Barres, "Dynamic epigenetic responses to muscle contraction," Drug Discovery Today, vol. 19, no. 7, pp. 1010-1014, 2014.

[69] N. R. Oliveira, S. O. Marques, T. F. Luciano et al., "Treadmill training increases SIRT- 1 and PGC- $1 \alpha$ protein levels and AMPK phosphorylation in quadriceps of middle-aged rats in an intensity-dependent manner," Mediators of Inflammation, vol. 2014, Article ID 987017, 11 pages, 2014.

[70] J. J. Brault, J. G. Jespersen, and A. L. Goldberg, "Peroxisome proliferator-activated receptor $\gamma$ coactivator $1 \alpha$ or $1 \beta$ overexpression inhibits muscle protein degradation, induction of ubiquitin ligases, and disuse atrophy," The Journal of Biological Chemistry, vol. 285, no. 25, pp. 19460-19471, 2010.

[71] P. Boström, J. Wu, M. P. Jedrychowski et al., "A PGC1- $\alpha$ dependent myokine that drives brown-fat-like development of white fat and thermogenesis," Nature, vol. 481, no. 7382, pp. 463-468, 2012.

[72] A. Safdar, J. M. Bourgeois, D. I. Ogborn et al., "Endurance exercise rescues progeroid aging and induces systemic mitochondrial rejuvenation in mtDNA mutator mice," Proceedings of the National Academy of Sciences of the United States of America, vol. 108, no. 10, pp. 41354140, 2011.

[73] Y. García-Mesa, J. C. López-Ramos, L. Giménez-Llort et al., "Physical exercise protects against Alzheimer's disease in 3xTg-AD mice," Journal of Alzheimer's Disease, vol. 24, no. 3, pp. 421-454, 2011.

[74] M. J. Zigmond, J. L. Cameron, R. K. Leak et al., “Triggering endogenous neuroprotective processes through exercise in models of dopamine deficiency," Parkinsonism \& Related Disorders, vol. 15, Supplement 3, pp. S42-S45, 2009.

[75] J. O. Holloszy, "Exercise increases average longevity of female rats despite increased food intake and no growth retardation," Journal of Gerontology, vol. 48, no. 3, pp. B97-B100, 1993.

[76] J. R. Ruiz, M. Morán, J. Arenas, and A. Lucia, "Strenuous endurance exercise improves life expectancy: it's in our genes," British Journal of Sports Medicine, vol. 45, no. 3, pp. 159-161, 2011.

[77] G. Parise, A. N. Brose, and M. A. Tarnopolsky, "Resistance exercise training decreases oxidative damage to DNA and increases cytochrome oxidase activity in older adults," Experimental Gerontology, vol. 40, no. 3, pp. 173-180, 2005.

[78] H. C. Dreyer, M. J. Drummond, B. Pennings et al., "Leucineenriched essential amino acid and carbohydrate ingestion following resistance exercise enhances mTOR signaling and protein synthesis in human muscle," American Journal of Physiology Endocrinology and Metabolism, vol. 294, no. 2, pp. E392-E400, 2008.

[79] K. Sakamoto, W. G. Aschenbach, M. F. Hirshman, and L. J. Goodyear, "Akt signaling in skeletal muscle: regulation by exercise and passive stretch," American Journal of Physiology Endocrinology and Metabolism, vol. 285, no. 5, pp. E1081E1088, 2003.

[80] E. Louis, U. Raue, Y. Yang, B. Jemiolo, and S. Trappe, "Time course of proteolytic, cytokine, and myostatin gene expression after acute exercise in human skeletal muscle," Journal of Applied Physiology (Bethesda, Md.:1985), vol. 103, no. 5, pp. 1744-1751, 2007.

[81] B. K. Pedersen and M. A. Febbraio, "Muscles, exercise and obesity: skeletal muscle as a secretory organ," Nature Reviews Endocrinology, vol. 8, no. 8, pp. 457-465, 2012.

[82] M. S. Hede, E. Salimova, A. Piszczek et al., "E-peptides control bioavailability of IGF-1," PLoS One, vol. 7, no. 12, article e51152, 2012.

[83] M. Vinciguerra, M. Hede, and N. Rosenthal, "Comments on point:counterpoint: IGF is/is not the major physiological regulator of muscle mass. IGF-1 is a major regulator of muscle mass during growth but not for adult myofiber hypertrophy," Journal of Applied Physiology (Bethesda, Md.:1985), vol. 108, no. 6, pp. 1829-1830, 2010.

[84] T. S. Bowen, G. Schuler, and V. Adams, "Skeletal muscle wasting in cachexia and sarcopenia: molecular pathophysiology and impact of exercise training," Journal of Cachexia Sarcopenia Muscle, vol. 6, no. 3, pp. 197-207, 2015.

[85] P. Grumati, L. Coletto, A. Schiavinato et al., "Physical exercise stimulates autophagy in normal skeletal muscles but is detrimental for collagen VI-deficient muscles," Autophagy, vol. 7, no. 12, pp. 1415-1423, 2011.

[86] C. He, M. C. Bassik, V. Moresi et al., "Exercise-induced BCL2-regulated autophagy is required for muscle glucose homeostasis," Nature, vol. 481, no. 7382, pp. 511-515, 2012.

[87] L. B. Verdijk, R. Koopman, G. Schaart, K. Meijer, H. H. Savelberg, and L. J. van Loon, "Satellite cell content is specifically reduced in type II skeletal muscle fibers in the elderly," American Journal of Physiology-Endocrinology and Metabolism, vol. 292, no. 1, pp. E151-E157, 2007.

[88] A. S. Brack, H. Bildsoe, and S. M. Hughes, "Evidence that satellite cell decrement contributes to preferential decline in nuclear number from large fibres during murine age-related 
muscle atrophy," Journal of Cell Science, vol. 118, no. 20, pp. 4813-4821, 2005.

[89] I. M. Conboy, M. J. Conboy, G. M. Smythe, and T. A. Rando, "Notch-mediated restoration of regenerative potential to aged muscle," Science, vol. 302, no. 5650, pp. 1575-1577, 2003.

[90] S. F. van der Meer, R. T. Jaspers, D. A. Jones, H. Degens, R. T. Jaspers, and D. A. Jones, "Time-course of changes in the myonuclear domain during denervation in young-adult and old rat gastrocnemius muscle," Muscle \& Nerve, vol. 43, no. 2, pp. 212-222, 2011.

[91] C. A. Collins, P. S. Zammit, A. P. Ruiz, J. E. Morgan, and T. A. Partridge, "A population of myogenic stem cells that survives skeletal muscle aging," Stem Cells, vol. 25, no. 4, pp. 885-894, 2007.

[92] T. Snijders, J. P. Nederveen, M. K. BR et al., "Satellite cells in human skeletal muscle plasticity," Frontiers in Physiology, vol. 6, p. 283, 2015.

[93] S. Laforest, D. M. St-Pierre, J. Cyr, and D. Gayton, "Effects of age and regular exercise on muscle strength and endurance," European Journal of Applied Physiology and Occupational Physiology, vol. 60, no. 2, pp. 104-111, 1990.

[94] E. Barbieri, D. Agostini, E. Polidori et al., "The pleiotropic effect of physical exercise on mitochondrial dynamics in aging skeletal muscle," Oxidative Medicine and Cellular Longevity, vol. 2015, Article ID 917085, 15 pages, 2015.

[95] M. C. Polidori, P. Mecocci, A. Cherubini, and U. Senin, "Physical activity and oxidative stress during aging," International Journal of Sports Medicine, vol. 21, no. 3, pp. 154-157, 2000.

[96] C. E. Cooper, N. B. Vollaard, T. Choueiri, and M. T. Wilson, "Exercise, free radicals and oxidative stress," Biochemical Society Transactions, vol. 30, pp. 280-285, 2002.

[97] R. Bergholm, S. Mäkimattila, M. Valkonen et al., "Intense physical training decreases circulating antioxidants and endothelium-dependent vasodilatation in vivo," Atherosclerosis, vol. 145, no. 2, pp. 341-349, 1999.

[98] M. C. Gomez-Cabrera, E. Domenech, and J. Vina, "Moderate exercise is an antioxidant: upregulation of antioxidant genes by training," Free Radical Biology \& Medicine, vol. 44, no. 2, pp. 126-131, 2008.

[99] P. Jakeman and S. Maxwell, "Effect of antioxidant vitamin supplementation on muscle function after eccentric exercise," European Journal of Applied Physiology and Occupational Physiology, vol. 67, no. 5, pp. 426-430, 1993.

[100] A. Shafat, P. Butler, R. L. Jensen, and A. E. Donnelly, "Effects of dietary supplementation with vitamins $\mathrm{C}$ and $\mathrm{E}$ on muscle function during and after eccentric contractions in humans," European Journal of Applied Physiology, vol. 93, no. 1-2, pp. 196-202, 2004.

[101] J. R. Jackson, M. J. Ryan, Y. Hao, and S. E. Alway, "Mediation of endogenous antioxidant enzymes and apoptotic signaling by resveratrol following muscle disuse in the gastrocnemius muscles of young and old rats," American Journal of Physiology - Regulatory, Integrative and Comparative Physiology, vol. 299, no. 6, pp. R1572-R1581, 2010.

[102] B. Marzani, M. Balage, A. Vénien et al., "Antioxidant supplementation restores defective leucine stimulation of protein synthesis in skeletal muscle from old rats," The Journal of Nutrition, vol. 138, no. 11, pp. 2205-2211, 2008.

[103] A. R. Mendelsohn and J. W. Larrick, "Trade-offs between anti-aging dietary supplementation and exercise," Rejuvenation Research, vol. 16, no. 5, pp. 419-426, 2013.
[104] M. Ristow, K. Zarse, A. Oberbach et al., "Antioxidants prevent health-promoting effects of physical exercise in humans," Proceedings of the National Academy of Sciences of the United States of America, vol. 106, no. 21, pp. 86658670, 2009.

[105] M. C. Gomez-Cabrera, E. Domenech, M. Romagnoli et al., "Oral administration of vitamin C decreases muscle mitochondrial biogenesis and hampers training-induced adaptations in endurance performance," The American Journal of Clinical Nutrition, vol. 87, no. 1, pp. 142-149, 2008.

[106] A. A. Theodorou, M. G. Nikolaidis, V. Paschalis et al., "No effect of antioxidant supplementation on muscle performance and blood redox status adaptations to eccentric training," The American Journal of Clinical Nutrition, vol. 93, no. 6, pp. 1373-1383, 2011.

[107] Y. Michailidis, L. G. Karagounis, G. Terzis et al., “Thiol-based antioxidant supplementation alters human skeletal muscle signaling and attenuates its inflammatory response and recovery after intense eccentric exercise," The American Journal of Clinical Nutrition, vol. 98, no. 1, pp. 233-245, 2013.

[108] D. Draganidis, L. G. Karagounis, I. Athanailidis, A. Chatzinikolaou, A. Z. Jamurtas, and I. G. Fatouros, "Inflammaging and skeletal muscle: can protein intake make a difference?," The Journal of Nutrition, vol. 146, no. 10, pp. 1940-1952, 2016.

[109] M. J. Jackson, "Strategies for reducing oxidative damage in ageing skeletal muscle," Advanced Drug Delivery Reviews, vol. 61, no. 14, pp. 1363-1368, 2009.

[110] M. Wyss and R. Kaddurah-Daouk, "Creatine and creatinine metabolism," Physiological Reviews, vol. 80, no. 3, pp. 11071213, 2000.

[111] E. S. Rawson, M. P. Conti, and M. P. Miles, "Creatine supplementation does not reduce muscle damage or enhance recovery from resistance exercise," Journal of Strength and Conditioning Research, vol. 21, no. 4, pp. 1208-1213, 2007.

[112] T. Wallimann and R. Harris, "Creatine: a miserable life without it," Amino Acids, vol. 48, no. 8, pp. 1739-1750, 2016.

[113] R. B. Kreider, D. S. Kalman, J. Antonio et al., "International Society of Sports Nutrition position stand: safety and efficacy of creatine supplementation in exercise, sport, and medicine," Journal of the International Society Sports Nutrition, vol. 14, p. 18, 2017.

[114] P. Sestili, E. Barbieri, and V. Stocchi, "Effects of creatine in skeletal muscle cells and in myoblasts differentiating under normal or oxidatively stressing conditions," Mini-Reviews in Medicinal Chemistry, vol. 16, no. 1, pp. 4-11, 2016.

[115] T. Wallimann, "Introduction-creatine: cheap ergogenic supplement with great potential for health and disease," Sub-Cellular Biochemistry, vol. 46, pp. 1-16, 2007.

[116] T. Wallimann, M. Tokarska-Schlattner, and U. Schlattner, "The creatine kinase system and pleiotropic effects of creatine," Amino Acids, vol. 40, no. 5, pp. 1271-1296, 2011.

[117] E. Barbieri, M. Guescini, C. Calcabrini et al., "Creatine prevents the structural and functional damage to mitochondria in myogenic, oxidatively stressed $\mathrm{C} 2 \mathrm{C} 12$ cells and restores their differentiation capacity," Oxidative Medicine and Cellular Longevity, vol. 2016, Article ID 5152029, 12 pages, 2016.

[118] L. Deldicque, M. Louis, D. Theisen et al., "Increased IGF mRNA in human skeletal muscle after creatine supplementation," Medicine and Science in Sports and Exercise, vol. 37, no. 5, pp. 731-736, 2005. 
[119] L. Deldicque, D. Theisen, L. Bertrand, P. Hespel, L. Hue, and M. Francaux, "Creatine enhances differentiation of myogenic C2C12 cells by activating both p38 and Akt/PKB pathways," American Journal of Physiology - Cell Physiology, vol. 293, no. 4, pp. C1263-C1271, 2007.

[120] M. Louis, R. Van Beneden, M. Dehoux, J. P. Thissen, and M. Francaux, "Creatine increases IGF-I and myogenic regulatory factor mRNA in C2C12 cells," FEBS Letters, vol. 557, no. 1-3, pp. 243-247, 2004.

[121] P. Sestili, E. Barbieri, C. Martinelli et al., "Creatine supplementation prevents the inhibition of myogenic differentiation in oxidatively injured C2C12 murine myoblasts," Molecular Nutrition \& Food Research, vol. 53, no. 9, pp. 1187-1204, 2009.

[122] J. M. Lawler, W. S. Barnes, G. Wu, W. Song, and S. Demaree, "Direct antioxidant properties of creatine," Biochemical and Biophysical Research Communications, vol. 290, no. 1, pp. 47-52, 2002.

[123] P. Sestili, C. Martinelli, G. Bravi et al., "Creatine supplementation affords cytoprotection in oxidatively injured cultured mammalian cells via direct antioxidant activity," Free Radical Biology \& Medicine, vol. 40, no. 5, pp. 837-849, 2006.

[124] A. Nomura, M. Zhang, T. Sakamoto et al., "Anti-inflammatory activity of creatine supplementation in endothelial cells in vitro," British Journal of Pharmacology, vol. 139, no. 4, pp. 715-720, 2003.

[125] R. V. Santos, R. A. Bassit, E. C. Caperuto, and L. F. Costa Rosa, "The effect of creatine supplementation upon inflammatory and muscle soreness markers after a $30 \mathrm{~km}$ race," Life Sciences, vol. 75, no. 16, pp. 1917-1924, 2004.

[126] P. Sestili, P. Ambrogini, E. Barbieri et al., "New insights into the trophic and cytoprotective effects of creatine in in vitro and in vivo models of cell maturation," Amino Acids, vol. 48, no. 8, pp. 1897-1911, 2016.

[127] D. G. Candow, "Sarcopenia: current theories and the potential beneficial effect of creatine application strategies," Biogerontology, vol. 12, no. 4, pp. 273-281, 2011.

[128] D. G. Candow, P. D. Chilibeck, and S. C. Forbes, "Creatine supplementation and aging musculoskeletal health," Endocrine, vol. 45, no. 3, pp. 354-361, 2014.

[129] R. T. Matthews, L. Yang, B. G. Jenkins et al., "Neuroprotective effects of creatine and cyclocreatine in animal models of Huntington's disease," Journal of Neuroscience, vol. 18, no. 1, pp. 156-163, 1998.

[130] C. Guidi, L. Potenza, P. Sestili et al., "Differential effect of creatine on oxidatively-injured mitochondrial and nuclear DNA," Biochimica et Biophysica Acta, vol. 1780, no. 1, pp. 16-26, 2008.

[131] M. Berneburg, T. Gremmel, V. Kürten et al., "Creatine supplementation normalizes mutagenesis of mitochondrial DNA as well as functional consequences," Journal of Investigative Dermatology, vol. 125, no. 2, pp. 213-220, 2005.

[132] H. Lenz, M. Schmidt, V. Welge et al., "The creatine kinase system in human skin: protective effects of creatine against oxidative and UV damage in vitro and in vivo," Journal of Investigative Dermatology, vol. 124, no. 2, pp. 443-452, 2005.

[133] C. Fimognari, P. Sestili, M. Lenzi, G. Cantelli-Forti, and P. Hrelia, "Protective effect of creatine against RNA damage," Mutation Research, vol. 670, no. 1-2, pp. 59-67, 2009.

[134] M. P. Cunha, V. Lieberknecht, A. B. Ramos-Hryb et al., "Creatine affords protection against glutamate-induced nitrosative and oxidative stress," Neurochemistry International, vol. 95, pp. 4-14, 2016.

[135] R. Hosamani, S. R. Ramesh, and M. Muralidhara, “Attenuation of rotenone-induced mitochondrial oxidative damage and neurotoxicity in Drosophila melanogaster supplemented with creatine," Neurochemical Research, vol. 35, no. 9, pp. 1402-1412, 2010.

[136] L. M. Rambo, L. R. Ribeiro, I. D. Della-Pace et al., "Acute creatine administration improves mitochondrial membrane potential and protects against pentylenetetrazol-induced seizures," Amino Acids, vol. 44, no. 3, pp. 857-868, 2013.

[137] K. Rakpongsiri and S. Sawangkoon, "Protective effect of creatine supplementation and estrogen replacement on cardiac reserve function and antioxidant reservation against oxidative stress in exercise-trained ovariectomized hamsters," International Heart Journal, vol. 49, no. 3, pp. 343-354, 2008.

[138] L. Guimarães-Ferreira, C. H. Pinheiro, F. Gerlinger-Romero et al., "Short-term creatine supplementation decreases reactive oxygen species content with no changes in expression and activity of antioxidant enzymes in skeletal muscle," European Journal of Applied Physiology, vol. 112, no. 11, pp. 3905-3911, 2012.

[139] R. Deminice and A. A. Jordao, "Creatine supplementation decreases plasma lipid peroxidation markers and enhances anaerobic performance in rats," Redox Report, vol. 21, no. 1, pp. 31-36, 2016.

[140] B. Mirzaei, F. Rahmani-Nia, Z. Salehi, and R. Rahimi, "Effects of creatine monohydrate supplementation on oxidative DNA damage and lipid peroxidation induced by acute incremental exercise to exhaustion in wrestlers," Kinesiology, vol. 45, no. 1, pp. 30-40, 2013.

[141] R. Rahimi, "Creatine supplementation decreases oxidative DNA damage and lipid peroxidation induced by a single bout of resistance exercise," Journal of Strength and Conditioning Research, vol. 25, no. 12, pp. 3448-3455, 2011.

[142] M. P. Barros, D. Ganini, L. Lorenço-Lima et al., "Effects of acute creatine supplementation on iron homeostasis and uric acid-based antioxidant capacity of plasma after wingate test," Journal of the International Society Sports Nutrition, vol. 9, no. 1, p. 25, 2012.

[143] M. Coco and V. Perciavalle, "Creatine ingestion effects on oxidative stress in a steady-state test at $75 \% \mathrm{VO}(2 \mathrm{max})$," The Journal of Sports Medicine and Physical Fitness, vol. 52, no. 2, pp. 165-169, 2012.

[144] M. P. Barros, D. Ganini, L. Lorenço-Lima et al., "Creatine as an antioxidant," Amino Acids, vol. 40, no. 5, pp. 1385-1396, 2011.

[145] J. F. Young, L. B. Larsen, A. Malmendal et al., "Creatineinduced activation of antioxidative defence in myotube cultures revealed by explorative NMR-based metabonomics and proteomics," Journal of the International Society Sports Nutrition, vol. 7, no. 1, pp. 7-9, 2010.

[146] Y. Samuni, S. Goldstein, O. M. Dean, and M. Berk, "The chemistry and biological activities of N-acetylcysteine," Biochimica et Biophysica Acta, vol. 1830, no. 8, pp. 4117-4129, 2013.

[147] C. R. Alves, J. C. Ferreira, M. A. de Siqueira-Filho, C. R. Carvalho, A. H. Lancha Jr, and B. Gualano, "Creatine-induced glucose uptake in type 2 diabetes: a role for AMPK- $\alpha$ ?," Amino Acids, vol. 43, no. 4, pp. 1803-1807, 2012.

[148] R. B. Ceddia and G. Sweeney, "Creatine supplementation increases glucose oxidation and AMPK phosphorylation and 
reduces lactate production in L6 rat skeletal muscle cells," Journal of Physiology, vol. 555, Part 2, pp. 409-421, 2004.

[149] A. Ahmad, M. Z. Sattar, H. A. Rathore et al., "Antioxidant activity and free radical scavenging capacity of L-arginine and Nahs: a comparative in vitro study," Acta Poloniae Pharmaceutica, vol. 72, no. 2, pp. 245-252, 2015.

[150] I. Hamad, N. Arda, M. Pekmez, S. Karaer, and G. Temizkan, "Intracellular scavenging activity of Trolox (6-hydroxy2,5,7,8-tetramethylchromane-2-carboxylic acid) in the fission yeast, Schizosaccharomyces pombe," Journal of Natural Science Biology and Medicine, vol. 1, no. 1, pp. 16-21, 2010.

[151] G. Biswas, O. A. Adebanjo, B. D. Freedman et al., "Retrograde $\mathrm{Ca} 2+$ signaling in $\mathrm{C} 2 \mathrm{C} 12$ skeletal myocytes in response to mitochondrial genetic and metabolic stress: a novel mode of inter-organelle crosstalk," The EMBO Journal, vol. 18, no. 3, pp. 522-533, 1999.

[152] C. Brunk and D. Yaffe, "The reversible inhibition of myoblast fusion by ethidium bromide (EB)," Experimental Cell Research, vol. 99, no. 2, pp. 310-318, 1976.

[153] N. H. Herzberg, E. Middelkoop, M. Adorf et al., "Mitochondria in cultured human muscle cells depleted of mitochondrial DNA," European Journal of Cell Biology, vol. 61, no. 2, pp. 400-408, 1993.

[154] N. H. Herzberg, R. Zwart, R. A. Wolterman et al., "Differentiation and proliferation of respiration-deficient human myoblasts," Biochimica et Biophysica Acta, vol. 1181, no. 1, pp. 63-67, 1993.

[155] W. Korohoda, Z. Pietrzkowski, and K. Reiss, "Chloramphenicol, an inhibitor of mitochondrial protein synthesis, inhibits myoblast fusion and myotube differentiation," Folia histochemica et Cytobiologica, vol. 31, no. 1, pp. 9-13, 1992.

[156] S. C. Leary, B. J. Battersby, R. G. Hansford, and C. D. Moyes, "Interactions between bioenergetics and mitochondrial biogenesis," Biochimica et Biophysica Acta, vol. 1365, no. 3, pp. 522-530, 1998.

[157] S. C. Leary, B. C. Hill, C. N. Lyons et al., "Chronic treatment with azide in situ leads to an irreversible loss of cytochrome c oxidase activity via holoenzyme dissociation," Journal of Biological Chemistry, vol. 277, no. 13, pp. 11321-11328, 2002.

[158] P. Pawlikowska, B. Gajkowska, J. F. Hocquette, and A. Orzechowski, "Not only insulin stimulates mitochondriogenesis in muscle cells, but mitochondria are also essential for insulin-mediated myogenesis," Cell Proliferation, vol. 39, no. 2, pp. 127-145, 2006.

[159] P. Rochard, A. Rodier, F. Casas et al., "Mitochondrial activity is involved in the regulation of myoblast differentiation through myogenin expression and activity of myogenic factors," Journal of Biological Chemistry, vol. 275, no. 4, pp. 2733-2744, 2000.

[160] P. Seyer, S. Grandemange, M. Busson et al., "Mitochondrial activity regulates myoblast differentiation by control of c-Myc expression," Journal of Cellular Physiology, vol. 207, no. 1, pp. 75-86, 2006.

[161] Z. Yun, Q. Lin, and A. J. Giaccia, “Adaptive myogenesis under hypoxia," Molecular and Cellular Biology, vol. 25, no. 8, pp. 3040-3055, 2005.

[162] S. Fulle, F. Protasi, G. Di Tano et al., "The contribution of reactive oxygen species to sarcopenia and muscle ageing," Experimental Gerontology, vol. 39, no. 1, pp. 17-24, 2004.
[163] M. Falkenberg, M. Gaspari, A. Rantanen, A. Trifunovic, N. G. Larsson, and C. M. Gustafsson, "Mitochondrial transcription factors B1 and B2 activate transcription of human mtDNA," Nature Genetics, vol. 31, no. 3, pp. 289-294, 2002.

[164] M. A. Parisi and D. A. Clayton, "Similarity of human mitochondrial transcription factor 1 to high mobility group proteins," Science, vol. 252, no. 5008, pp. 965-969, 1991.

[165] M. van Leemputte, K. Vandenberghe, and P. Hespel, "Shortening of muscle relaxation time after creatine loading," Journal of Applied Physiology (Bethesda, Md.: 1985), vol. 86, no. 3, pp. 840-844, 1999.

[166] A. Hiona, A. Sanz, G. C. Kujoth et al., "Mitochondrial DNA mutations induce mitochondrial dysfunction, apoptosis and sarcopenia in skeletal muscle of mitochondrial DNA mutator mice," PLoS One, vol. 5, no. 7, article e11468, 2010.

[167] D. G. Brdiczka, D. B. Zorov, and S. S. Sheu, "Mitochondrial contact sites: their role in energy metabolism and apoptosis," Biochimica et Biophysica Acta-Molecular Basis of Disease, vol. 1762, no. 2, pp. 148-163, 2006.

[168] J. S. Ingwall, "Creatine and the control of muscle-specific protein synthesis in cardiac and skeletal muscle," Circulation Research, vol. 38, no. 5, Supplement 1, pp. I115-I123, 1976.

[169] C. B. Mobley, C. D. Fox, B. S. Ferguson et al., "L-leucine, betahydroxy-beta-methylbutyric acid (HMB) and creatine monohydrate prevent myostatin-induced Akirin-1/Mighty mRNA down-regulation and myotube atrophy," Journal of International Society of Sports Nutrition, vol. 11, p. 38, 2014.

[170] P. Hespel, B. Op't Eijnde, M. Van Leemputte et al., "Oral creatine supplementation facilitates the rehabilitation of disuse atrophy and alters the expression of muscle myogenic factors in humans," Journal of Physiology, vol. 536, Part 2, pp. 625-633, 2001.

[171] D. S. Willoughby and J. M. Rosene, "Effects of oral creatine and resistance training on myogenic regulatory factor expression," Medicine and Science in Sports and Exercise, vol. 35, no. 6, pp. 923-929, 2003.

[172] A. Moon, L. Heywood, S. Rutherford, and C. Cobbold, "Creatine supplementation: can it improve quality of life in the elderly without associated resistance training?," Current Aging Science, vol. 6, no. 3, pp. 251-257, 2013.

[173] D. G. Candow, E. Vogt, S. Johannsmeyer, S. C. Forbes, and J. P. Farthing, "Strategic creatine supplementation and resistance training in healthy older adults," Applied Physiology, Nutrition, and Metabolism, vol. 40, no. 7, pp. 689-694, 2015.

[174] J. Antonio and V. Ciccone, "The effects of pre versus post workout supplementation of creatine monohydrate on body composition and strength," Journal of the International Society of Sports Nutrition, vol. 10, p. 36, 2013.

[175] D. G. Candow, S. C. Forbes, J. P. Little, S. M. Cornish, C. Pinkoski, and P. D. Chilibeck, "Effect of nutritional interventions and resistance exercise on aging muscle mass and strength," Biogerontology, vol. 13, no. 4, pp. 345-358, 2012.

[176] D. G. Candow, G. A. Zello, B. Ling et al., "Comparison of creatine supplementation before versus after supervised resistance training in healthy older adults," Research in Sports Medicine, vol. 22, no. 1, pp. 61-74, 2014.

[177] P. J. Cribb and A. Hayes, "Effects of supplement timing and resistance exercise on skeletal muscle hypertrophy," Medicine and Science in Sports and Exercise, vol. 38, no. 11, pp. 1918-1925, 2006. 
[178] A. Brose, G. Parise, and M. A. Tarnopolsky, "Creatine supplementation enhances isometric strength and body composition improvements following strength exercise training in older adults," Journals of Gerontology Series a-Biological Sciences and Medical Sciences, vol. 58, no. 1, pp. B11-B19, 2003.

[179] M. Tarnopolsky, A. Zimmer, J. Paikin et al., "Creatine monohydrate and conjugated linoleic acid improve strength and body composition following resistance exercise in older adults," PLoS One, vol. 2, no. 10, article e991, 2007.

[180] M. C. Devries and S. M. Phillips, "Creatine supplementation during resistance training in older adults-a meta-analysis," Medicine and Science in Sports and Exercise, vol. 46, no. 6, pp. 1194-1203, 2014.

[181] C. L. Pinto, P. B. Botelho, J. A. Carneiro, and J. F. Mota, "Impact of creatine supplementation in combination with resistance training on lean mass in the elderly," Journal of Cachexia Sarcopenia and Muscle, vol. 7, no. 4, pp. 413-421, 2016.

[182] B. Gualano, A. R. Macedo, C. R. Alves et al., "Creatine supplementation and resistance training in vulnerable older women: a randomized double-blind placebo-controlled clinical trial," Experimental Gerontology, vol. 53, pp. 7-15, 2014.

[183] S. Johannsmeyer, D. G. Candow, C. M. Brahms, D. Michel, and G. A. Zello, "Effect of creatine supplementation and drop-set resistance training in untrained aging adults," Experimental Gerontology, vol. 83, pp. 112-119, 2016.

[184] A. Bender, J. Beckers, I. Schneider et al., "Creatine improves health and survival of mice," Neurobiology of Aging, vol. 29, no. 9, pp. 1404-1411, 2008.

[185] F. L. Crane, Y. Hatefi, R. L. Lester, and C. Widmer, "Isolation of a quinone from beef heart mitochondria," Biochimica et Biophysica Acta, vol. 25, no. 1, pp. 220-221, 1957.

[186] M. Battino, E. Ferri, A. Gorini et al., "Natural distribution and occurrence of coenzyme Q homologues," Membrane Biochemistry, vol. 9, no. 3, pp. 179-190, 1990.

[187] M. L. Genova and G. Lenaz, "New developments on the functions of coenzyme Q in mitochondria," BioFactors, vol. 37, no. 5, pp. 330-354, 2011.

[188] M. Turunen, J. Olsson, and G. Dallner, "Metabolism and function of coenzyme Q," Biochimica et Biophysica Acta, vol. 1660, no. 1-2, pp. 171-199, 2004.

[189] L. Ernster and P. Forsmark-Andree, "Ubiquinol: an endogenous antioxidant in aerobic organisms," The Clinical Investigator, vol. 71, 8 Supplement, pp. S60-S65, 1993.

[190] V. Naumor and G. Khrapova, "Chemiluminescent study of ubiquinone and ubiquinol interaction with peroxide radicals," Biophysica, vol. 28, pp. 730-735, 1987.

[191] R. Stocker, V. W. Bowry, and B. Frei, "Ubiquinol-10 protects human low density lipoprotein more efficiently against lipid peroxidation than does alpha-tocopherol," Proceedings of the National Academy of Sciences of the United States of America, vol. 88, no. 5, pp. 1646-1650, 1991.

[192] E. Niki, "Mechanisms and dynamics of antioxidant action of ubiquinol," Molecular Aspects of Medicine, vol. 18, Supplement, pp. S63-S70, 1997.

[193] H. Shi, N. Noguchi, and E. Niki, "Dynamics of antioxidant action of ubiquinol: a reappraisal," BioFactors, vol. 9, no. 2-4, pp. 141-148, 1999.

[194] H. Shi, N. Noguchi, and E. Niki, "Comparative study on dynamics of antioxidative action of alpha-tocopheryl hydroquinone, ubiquinol, and $\alpha$-tocopherol against lipid peroxidation," Free Radical Biology \& Medicine, vol. 27, no. 3-4, pp. 334-346, 1999.

[195] P. Mitchell, "Protonmotive redox mechanism of the cytochrome b-c1 complex in the respiratory chain: protonmotive ubiquinone cycle," FEBS Letters, vol. 56, no. 1, pp. 1-6, 1975.

[196] W. A. Cramer, S. S. Hasan, and E. Yamashita, "The Q cycle of cytochrome bc complexes: a structure perspective," Biochimica et Biophysica Acta, vol. 1807, no. 7, pp. 788-802, 2011.

[197] J. M. Villalba, F. Navarro, C. Gómez-Díaz, A. Arroyo, R. I. Bello, and P. Navas, "Role of cytochrome b5 reductase on the antioxidant function of coenzyme Q in the plasma membrane," Molecular Aspects of Medicine, vol. 18, Supplement, pp. S7-S13, 1997.

[198] G. Lenaz, R. Fato, S. Di Bernardo et al., "Localization and mobility of coenzyme Q in lipid bilayers and membranes," BioFactors, vol. 9, no. 2-4, pp. 87-93, 1999.

[199] G. Lenaz and M. L. Genova, "Structure and organization of mitochondrial respiratory complexes: a new understanding of an old subject," Antioxidants \& Redox Signaling, vol. 12, no. 8, pp. 961-1008, 2010.

[200] I. Buhaescu and H. Izzedine, "Mevalonate pathway: a review of clinical and therapeutical implications," Clinical Biochemistry, vol. 40, no. 9-10, pp. 575-584, 2007.

[201] C. Weber, A. Bysted, and G. Holmer, "Coenzyme Q10 in the diet-daily intake and relative bioavailability," Molecular Aspects of Medicine, vol. 18, Supplement, pp. S251-S254, 1997.

[202] C. M. Quinzii, L. C. López, A. Naini, S. DiMauro, and M. Hirano, "Human CoQ10 deficiencies," BioFactors, vol. 32, no. 1-4, pp. 113-118, 2008.

[203] K. Folkers, "Heart failure is a dominant deficiency of coenzyme Q10 and challenges for future clinical research on CoQ10," The Clinical Investigator, vol. 71, 8 Supplement, pp. S51-S54, 1993.

[204] U. Manzoli, E. Rossi, G. P. Littarru et al., "Coenzyme Q10 in dilated cardiomyopathy," International Journal of Tissue Reactions, vol. 12, no. 3, pp. 173-178, 1990.

[205] C. M. Quinzii, L. C. López, J. Von-Moltke et al., "Respiratory chain dysfunction and oxidative stress correlate with severity of primary CoQ10 deficiency," The FASEB Journal, vol. 22, no. 6, pp. 1874-1885, 2008.

[206] G. P. Littarru, S. Lippa, A. Oradei, and F. Serino, "Coenzyme Q10: blood levels and metabolic demand," International Journal of Tissue Reactions, vol. 12, no. 3, pp. 145-148, 1990.

[207] G. P. Littarru and P. Langsjoen, "Coenzyme Q10 and statins: biochemical and clinical implications," Mitochondrion, vol. 7, Supplement, pp. S168-S174, 2007.

[208] L. Marcoff and P. D. Thompson, "The role of coenzyme Q10 in statin-associated myopathy: a systematic review," Journal of the American College of Cardiology, vol. 49, no. 23, pp. 2231-2237, 2007.

[209] C. Lamperti, A. B. Naini, V. Lucchini et al., "Muscle coenzyme Q10 level in statin-related myopathy," Archives of Neurology, vol. 62, no. 11, pp. 1709-1712, 2005.

[210] A. Kalen, E. L. Appelkvist, and G. Dallner, "Age-related changes in the lipid compositions of rat and human tissues," Lipids, vol. 24, no. 7, pp. 579-584, 1989.

[211] P. Niklowitz, S. Onur, A. Fischer et al., "Coenzyme Q10 serum concentration and redox status in European adults: influence of age, sex, and lipoprotein concentration," Journal 
of Clinical Biochemistry and Nutrition, vol. 58, no. 3, pp. 240245, 2016.

[212] R. S. Sohal and M. J. Forster, "Coenzyme Q, oxidative stress and aging," Mitochondrion, vol. 7, Supplement, pp. S103S111, 2007.

[213] J. Oh, M. R. Ban, B. A. Miskie, R. L. Pollex, and R. A. Hegele, "Genetic determinants of statin intolerance," Lipids in Health and Disease, vol. 6, p. 7, 2007.

[214] L. Puccetti, F. Ciani, and A. Auteri, "Genetic involvement in statins induced myopathy. Preliminary data from an observational case-control study," Atherosclerosis, vol. 211, no. 1, pp. 28-29, 2010.

[215] E. Bruckert, G. Hayem, S. Dejager, C. Yau, and B. Bégaud, "Mild to moderate muscular symptoms with high-dosage statin therapy in hyperlipidemic patients-the PRIMO study," Cardiovascular Drugs and Therapy, vol. 19, no. 6, pp. 403414, 2005.

[216] B. A. Parker and P. D. Thompson, "Effect of statins on skeletal muscle: exercise, myopathy, and muscle outcomes," Exercise and Sport Sciences Reviews, vol. 40, no. 4, pp. 188-194, 2012.

[217] J. Garrido-Maraver, M. D. Cordero, M. Oropesa-Ávila et al., "Coenzyme q10 therapy," Molecular Syndromology, vol. 5, no. 3-4, pp. 187-197, 2014.

[218] G. P. Littarru and L. Tiano, "Clinical aspects of coenzyme Q10: an update," Nutrition, vol. 26, no. 3, pp. 250-254, 2010.

[219] H. Alho and K. Lonnrot, "Coenzyme Q supplementation and longevity," in Coenzyme Q: Molecular Mechanisms in Health and Disease, V. E. Kagan and P. J. Quinn, Eds., CRC Press, Boca Raton, FL, USA, 2000.

[220] M. Kon, K. Tanabe, T. Akimoto et al., "Reducing exerciseinduced muscular injury in kendo athletes with supplementation of coenzyme Q10," The British Journal of Nutrition, vol. 100, no. 4, pp. 903-909, 2008.

[221] P. Tauler, M. D. Ferrer, A. Sureda et al., "Supplementation with an antioxidant cocktail containing coenzyme Q prevents plasma oxidative damage induced by soccer," European Journal of Applied Physiology, vol. 104, no. 5, pp. 777-785, 2008.

[222] P. Bernardi and M. Forte, "The mitochondrial permeability transition pore," Novartis Foundation Symposium, vol. 287, pp. 157-164, 2007.

[223] J. Tower, "Programmed cell death in aging," Ageing Research Reviews, vol. 23, Part A, pp. 90-100, 2015.

[224] N. Cheema, A. Herbst, D. McKenzie, and J. M. Aiken, “Apoptosis and necrosis mediate skeletal muscle fiber loss in ageinduced mitochondrial enzymatic abnormalities," Aging Cell, vol. 14, no. 6, pp. 1085-1093, 2015.

[225] A. Herbst, C. J. Johnson, K. Hynes, D. Mc Kenzie, and J. M. Aiken, "Mitochondrial biogenesis drives a vicious cycle of metabolic insufficiency and mitochondrial DNA deletion mutation accumulation in aged rat skeletal muscle fibers," PLoS One, vol. 8, no. 3, article e59006, 2013.

[226] A. Herbst, J. Wanagat, N. Cheema, K. Widjaja, D. McKenzie, and J. M. Aiken, "Latent mitochondrial DNA deletion mutations drive muscle fiber loss at old age," Aging Cell, vol. 15, no. 6, pp. 1132-1139, 2016.

[227] D. McKenzie, E. Bua, S. McKiernan, Z. Cao, J. M. Aiken, and J. Wanagat, "Mitochondrial DNA deletion mutations: a causal role in sarcopenia," European Journal of Biochemistry, vol. 269, no. 8, pp. 2010-2015, 2002.
[228] S. Spendiff, M. Vuda, G. Gouspillou et al., "Denervation drives mitochondrial dysfunction in skeletal muscle of octogenarians," The Journal of Physiology, vol. 594, no. 24, pp. 7361-7379, 2016.

[229] L. Walter, V. Nogueira, X. Leverve, M. P. Heitz, P. Bernardi, and E. Fontaine, "Three classes of ubiquinone analogs regulate the mitochondrial permeability transition pore through a common site," The Journal of Biological Chemistry, vol. 275, no. 38, pp. 29521-29527, 2000.

[230] F. Devun, L. Walter, J. Belliere, C. Cottet-Rousselle, X. Leverve, and E. Fontaine, "Ubiquinone analogs: a mitochondrial permeability transition pore-dependent pathway to selective cell death," PLoS One, vol. 5, no. 7, article e11792, 2010.

[231] G. Li, L. Y. Zou, C. M. Cao, and E. S. Yang, “Coenzyme Q10 protects SHSY5Y neuronal cells from beta amyloid toxicity and oxygen-glucose deprivation by inhibiting the opening of the mitochondrial permeability transition pore," BioFactors, vol. 25, no. 1-4, pp. 97-107, 2005.

[232] M. D. Cordero, A. M. Moreno-Fernández, J. L. GomezSkarmeta et al., "Coenzyme Q10 and alpha-tocopherol protect against amitriptyline toxicity," Toxicology and Applied Pharmacology, vol. 235, no. 3, pp. 329-337, 2009.

[233] V. F. Sahach, H. L. Vavilova, O. V. Rudyk, F. V. Dobrovol's'kyı̆, T. V. Shymans'ka, and O. S. Miedviediev, "Inhibition of mitochondrial permeability transition pore is one of the mechanisms of cardioprotective effect of coenzyme Q10,” Fiziologicheskiu Zhurnal, vol. 53, no. 4, pp. 35-42, 2007.

[234] C. Franceschi and J. Campisi, "Chronic inflammation (inflammaging) and its potential contribution to ageassociated diseases," The Journals of Gerontology Series A: Biological Sciences and Medical Sciences, vol. 69, Supplement 1, pp. S4-S9, 2014.

[235] K. S. Ahn and B. B. Aggarwal, "Transcription factor NF- $\kappa$ B: a sensor for smoke and stress signals," Annals of the New York Academy of Sciences, vol. 1056, pp. 218-233, 2005.

[236] D. Cai, J. D. Frantz, N. E. Tawa Jr et al., "IKK $\beta / N F-\kappa B$ activation causes severe muscle wasting in mice," Cell, vol. 119, no. 2, pp. 285-298, 2004.

[237] D. J. Glass, "Skeletal muscle hypertrophy and atrophy signaling pathways," The International Journal of Biochemistry \& Cell Biology, vol. 37, no. 10, pp. 1974-1984, 2005.

[238] A. Fischer, S. Onur, C. Schmelzer, and F. Döring, "Ubiquinol decreases monocytic expression and DNA methylation of the pro-inflammatory chemokine ligand 2 gene in humans," BMC Research Notes, vol. 5, p. 540, 2012.

[239] C. Schmelzer, C. Kohl, G. Rimbach, and F. Döring, "The reduced form of coenzyme Q10 decreases the expression of lipopolysaccharide-sensitive genes in human THP-1 cells," Journal of Medicinal Food, vol. 14, no. 4, pp. 391-397, 2011.

[240] C. Schmelzer, M. Kitano, G. Rimbach et al., "Effects of ubiquinol-10 on microRNA-146a expression in vitro and in vivo," Mediators of Inflammation, vol. 2009, Article ID 415437, 7 pages, 2009.

[241] C. Gorelick, M. Lopez-Jones, G. L. Goldberg, S. L. Romney, and D. Khabele, "Coenzyme Q10 and lipid-related gene induction in HeLa cells," American Journal of Obstetrics and Gynecology, vol. 190, no. 5, pp. 1432-1434, 2004.

[242] D. A. Groneberg, B. Kindermann, M. Althammer et al., "Coenzyme Q10 affects expression of genes involved in cell signalling, metabolism and transport in human $\mathrm{CaCo}-2$ 
cells," The International Journal of Biochemistry \& Cell Biology, vol. 37, no. 6, pp. 1208-1218, 2005.

[243] A. W. Linnane, G. Kopsidas, C. Zhang et al., "Cellular redox activity of coenzyme Q10: effect of CoQ10 supplementation on human skeletal muscle," Free Radical Research, vol. 36, no. 4, pp. 445-453, 2002.

[244] H. Nohl, N. Rohr-Udilova, L. Gille et al., "Suppression of tumour-promoting factors in fat-induced colon carcinogenesis by the antioxidants caroverine and ubiquinone," Anticancer Research, vol. 25, no. 4, pp. 2793-2800, 2005.

[245] S. K. Park, K. Kim, G. P. Page, D. B. Allison, R. Weindruch, and T. A. Prolla, "Gene expression profiling of aging in multiple mouse strains: identification of aging biomarkers and impact of dietary antioxidants," Aging Cell, vol. 8, no. 4, pp. 484-495, 2009.

[246] A. W. Linnane, C. Zhang, N. Yarovaya et al., "Human aging and global function of coenzyme Q10," Annals of the New York Academy of Sciences, vol. 959, pp. 396-411, 2002.

[247] H. Maruoka, K. Fujii, K. Inoue, and S. Kido, "Long-term effect of ubiquinol on exercise capacity and the oxidative stress regulation system in SAMP1 mice," Journal of Physical Therapy Science, vol. 26, no. 3, pp. 367-371, 2014.

[248] M. Kon, F. Kimura, T. Akimoto et al., "Effect of coenzyme Q10 supplementation on exercise-induced muscular injury of rats," Exercise Immunology Review, vol. 13, pp. 76-88, 2007.

[249] D. Alf, M. E. Schmidt, and S. C. Siebrecht, "Ubiquinol supplementation enhances peak power production in trained athletes: a double-blind, placebo controlled study," Journal of the International Society Sports Nutrition, vol. 10, p. 24, 2013.

[250] K. Mizuno, M. Tanaka, S. Nozaki et al., "Antifatigue effects of coenzyme Q10 during physical fatigue," Nutrition, vol. 24, no. 4, pp. 293-299, 2008.

[251] T. Ylikoski, J. Piirainen, O. Hanninen, and J. Penttinen, “The effect of coenzyme Q10 on the exercise performance of crosscountry skiers," Molecular Aspects of Medicine, vol. 18, Supplement, pp. S283-S290, 1997.

[252] J. Díaz-Castro, R. Guisado, N. Kajarabille et al., "Coenzyme $\mathrm{Q}(10)$ supplementation ameliorates inflammatory signaling and oxidative stress associated with strenuous exercise," European Journal of Nutrition, vol. 51, no. 7, pp. 791-799, 2012. 


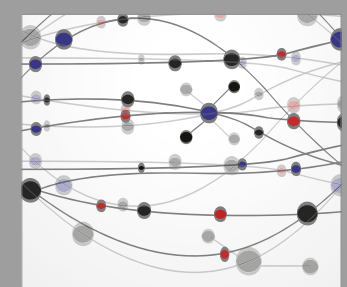

The Scientific World Journal
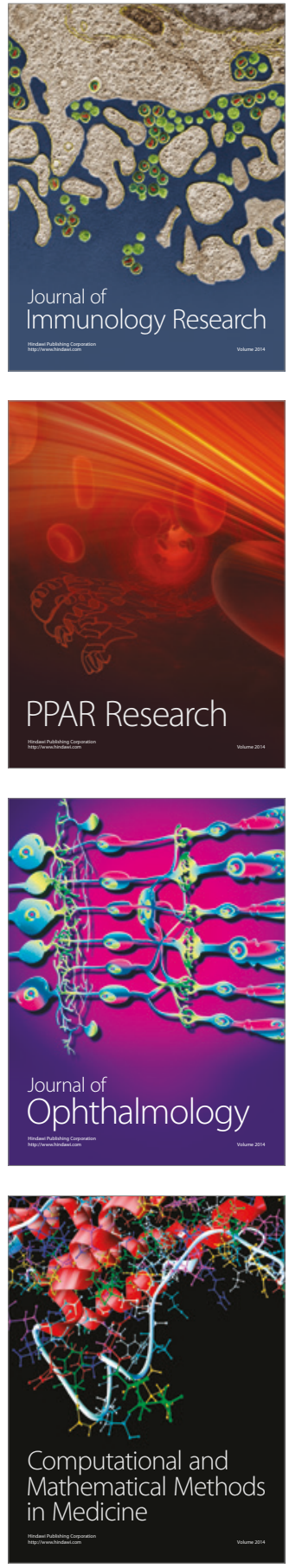

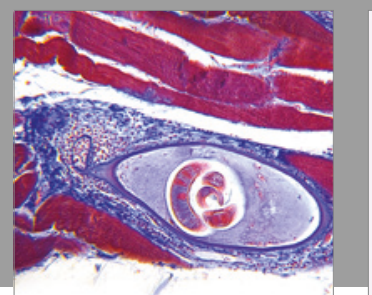

Gastroenterology Research and Practice
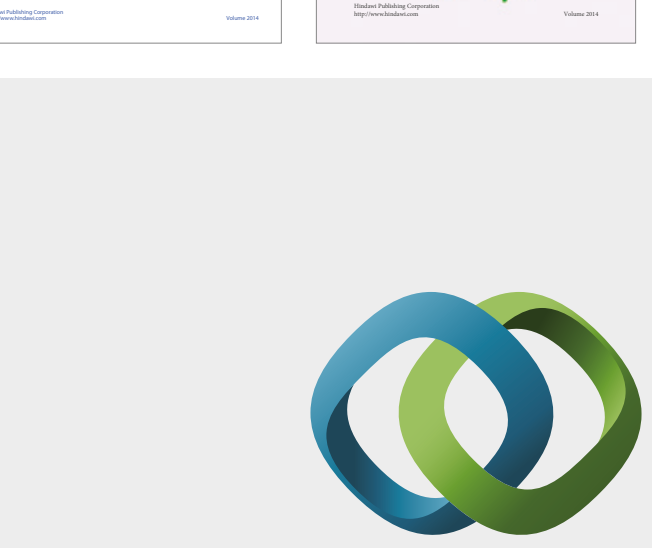

\section{Hindawi}

Submit your manuscripts at

https://www.hindawi.com
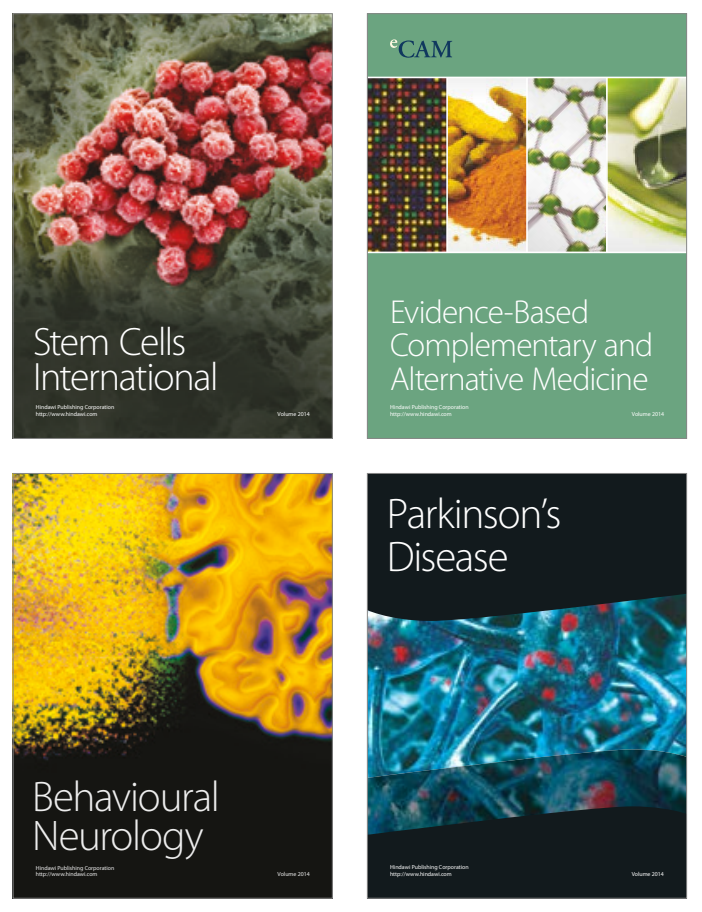
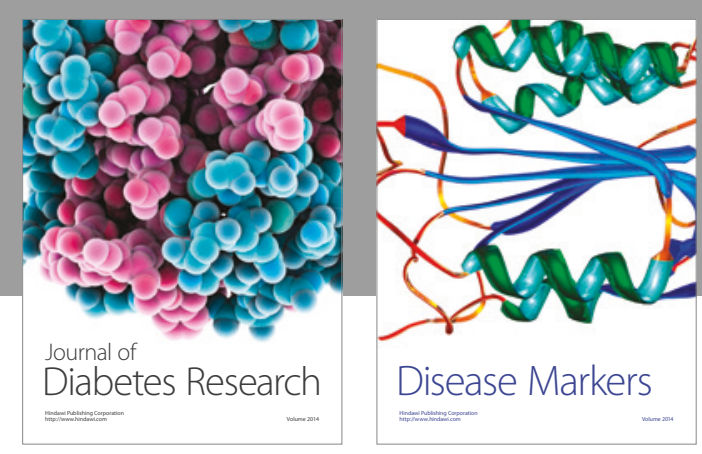

Disease Markers
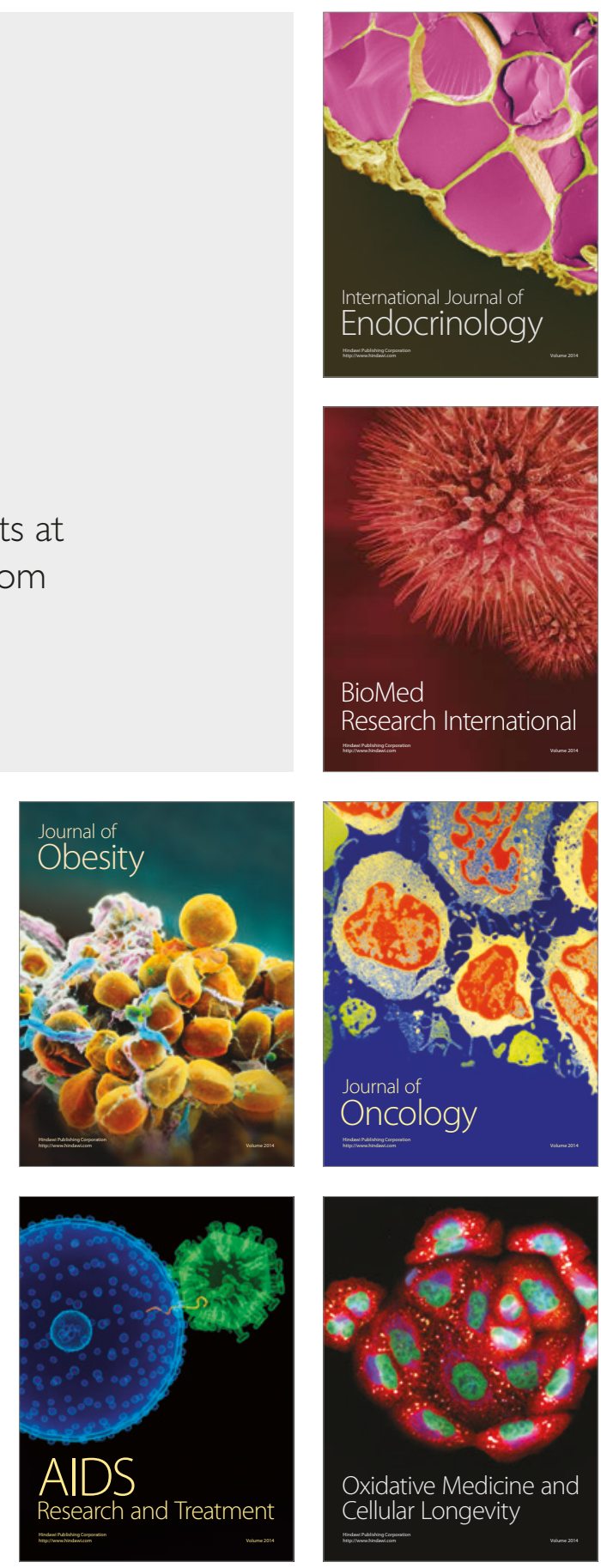